NBER WORKING PAPER SERIES

IMPLICATIONS OF POPULATION AGING FOR ECONOMIC GROWTH

David E. Bloom

David Canning

Günther Fink

Working Paper 16705

http://www.nber.org/papers/w16705

\author{
NATIONAL BUREAU OF ECONOMIC RESEARCH \\ 1050 Massachusetts Avenue \\ Cambridge, MA 02138 \\ January 2011
}

Support for this work was provided by the Program on the Global Demography of Aging at Harvard University, funded by Award Number P30AG024409 from the National Institute on Aging. The content is solely the responsibility of the authors and does not necessarily represent the official views of the National Institute on Aging or the National Institutes of Health. The authors thank Marija Ozolins and Larry Rosenberg for their assistance in the preparation of this paper. The views expressed herein are those of the authors and do not necessarily reflect the views of the National Bureau of Economic Research.

NBER working papers are circulated for discussion and comment purposes. They have not been peerreviewed or been subject to the review by the NBER Board of Directors that accompanies official NBER publications.

(C) 2011 by David E. Bloom, David Canning, and Günther Fink. All rights reserved. Short sections of text, not to exceed two paragraphs, may be quoted without explicit permission provided that full credit, including $\odot$ notice, is given to the source. 
Implications of Population Aging for Economic Growth

David E. Bloom, David Canning, and Günther Fink

NBER Working Paper No. 16705

January 2011

JEL No. J14,J15,J21,J26,O1,O4

\begin{abstract}
The share of the population aged 60 and over is projected to increase in nearly every country in the world during 2005-2050. Population ageing will tend to lower both labor-force participation and savings rates, thereby raising concerns about a future slowing of economic growth. Our calculations suggest that OECD countries are likely to see modest - but not catastrophic - declines in the rate of economic growth. However, behavioral responses (including greater female labor force participation) and policy reforms (including an increase in the legal age of retirement) can mitigate the economic consequences of an older population. In most non-OECD countries, declining fertility rates will cause labor-force-to-population ratios to rise as the shrinking share of young people will more than offset the skewing of adults toward the older ages. These factors suggest that population ageing will not significantly impede the pace of economic growth in developing countries.
\end{abstract}

David E. Bloom

Harvard School of Public Health

Department of Global Health and Population

665 Huntington Ave.

Boston, MA 02115

and NBER

dbloom@hsph.harvard.edu

David Canning

Harvard School of Public Health

Department of Global Health and Population

665 Huntington Ave.

Boston, MA 02115

dcanning@hsph.harvard.edu
Günther Fink

Harvard School of Public Health

Department of Global Health and Population

665 Huntington Ave.

Boston, MA 02115

gfink@hsph.harvard.edu 


\title{
Population Aging and Economic Growth
}

\author{
David E. Bloom, David Canning, and Günther Fink
}

\section{Introduction}

The world is entering largely unfamiliar territory with respect to population aging. Combined with the dynamic evolution of past variations in birth and death rates, recent declines in fertility rates and increases in life expectancy are causing a significant shift in the global age structure. The number of people over the age of 60 is projected to reach 1 billion by 2020 and almost 2 billion by 2050 , representing 22 percent of the world's population. The proportion of individuals aged 80 or over is projected to rise from 1 percent to 4 percent of the global population between today and $2050 .^{1}$

The elderly are not only growing rapidly in absolute numbers, but have also become substantially healthier. In a phenomenon referred to by demographers and health specialists as the "compression of morbidity", the length of healthy old-age appears to be increasing. Part of this trend can be attributed to increases in the length of life, and part to shorter and later periods of illness. The net effect is an increase in number of years lived at old age without major health problems.

Since different age groups have different needs and productive capacities, a country's economic characteristics will likely change as its population ages. A standard approach to assessing these changes is to assume constant age-specific behavior with respect to employment, consumption, and savings, and to assess the implications of changes in the relative size of different age groups for these fundamental contributors to national income. However, this simple approach is likely to be misleading as changing norms and expectations are likely to alter individual behavior in a way that will influence the economic consequences of aging. In particular, expectations of living longer than previous generations may induce individuals to remain in the workforce for longer and to begin to draw down savings at a later age. In addition, the links between population aging and macroeconomic performance are mediated by the institutional context. With increasing longevity and aging populations, retirement policy, pension and health care finance, the efficiency of labor and capital markets, and the structure of regional and global economic systems are likely to adjust. The magnitude of these shifts may in turn depend on voting and other political behavior of an aging electorate whose needs and interests may differ from those of younger people.

This paper examines the effects of population aging on economic growth. We begin with a presentation and analysis of descriptive statistics on the extent and pace of population aging. The paper then explores the overall effect of population aging on economic growth as well as the effects operating via two main channels through which growth can occur: labor supply and human capital accumulation. Accounting effects of population aging on factor accumulation and economic growth are distinguished from behavioral effects. Finally, the paper highlights the

\footnotetext{
${ }^{1}$ The United Nations makes several separate forecasts of population size, including ones based on low-, medium-, and high-fertility assumptions. This paper uses the UN's medium-fertility scenario except where otherwise stated.
} 
important role played by the policy and institutional environment in determining the economic growth effects of population aging. This section also discusses a variety of demographic, behavioral, and policy forces crucial to understanding and guiding the effect of population aging on economic growth.

\section{Population Aging: Facts, Force, and Future}

In this section, we present a series of key facts regarding past and projected future population aging, and briefly consider some of the related policy implications. The data and figures presented will serve as anchors for the economic analyses found in subsequent sections. We first look at the overall UN population projections, and then examine the factors underlying the rise in the absolute size and share of the elderly population. We also briefly investigate how population trends will affect the options faced by policymakers.

\section{Population data and projections}

Population projections from the United Nations change every two years as new estimates are published. For example, forecasts of the total world population in 2050 declined from about 10 to 9 billion people between 1994 and 2008. One might expect projections of the number of people aged 60 or above and 80 or above to be rather stable, since all those who will reach those ages in the next six decades have already been born and unpredictable changes in fertility need not be taken into account. However, these projections have changed significantly, even in recent years: the greatest proportionate change between the 1994 and $2008 \mathrm{UN}$ forecasts occurred for the population aged $80+$ in 2050 , with a $20 \%$ increase in the population size estimate for developed countries since 1994. The population projection data displayed in this paper should thus be interpreted with caution as current estimates may well be significantly altered as new fertility and mortality data become available. 
Despite these concerns around long-term projections, a simple look at today's age structure makes it very clear that world is experiencing an unprecedented phenomenon in terms of aging. ${ }^{2}$ The $60+$ and $80+$ age groups' shares of the total population are higher than at any time in history, and their growth is accelerating. The global population aged 60 and over has increased from 200 million in 1950 to around 760 million today. By 2050, it is projected to reach 2 billion (see Exhibit 1). The number aged 80+ has risen from 14 million in 1950 to around 11 million today, and will be near 400 million by 2050 if current projections prevail. Older age cohorts, moreover, are beginning to account for a substantial proportion of the total population. Indeed, all countries are forecast to see a higher share of people aged 60+ in 2050 than in 2000, with the percentagepoint increase ranging from 1 in Niger to 34 in Macao. It should be noted that similar patterns were not always observed in the past, with numerous countries experiencing large drops in the fraction $60+$ between 1950 and 2000 .

\section{Exhibit 1 - World, population by age group}

World, population by age group

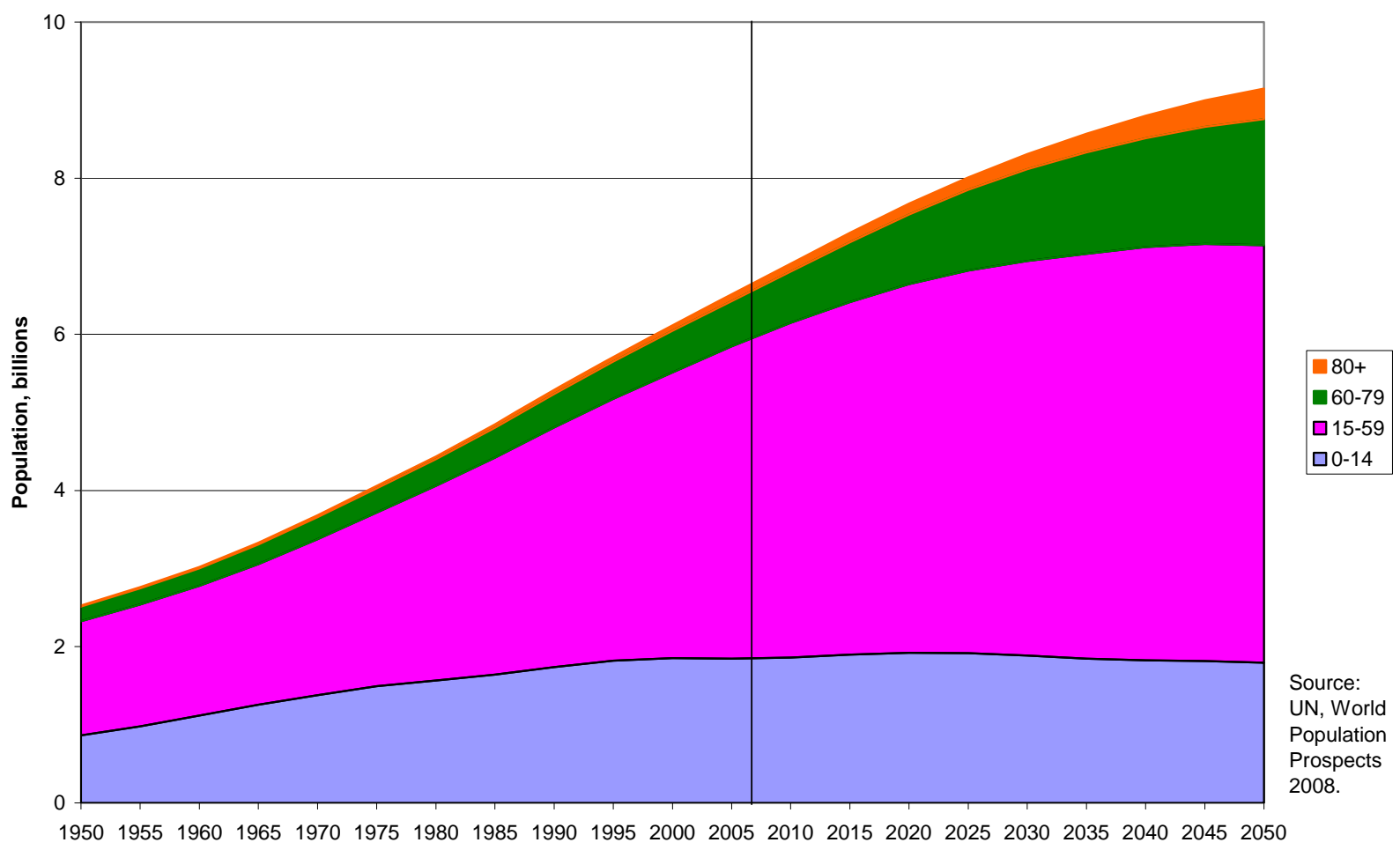

These projections displayed in Exhibit 1 are based on the UN's medium-fertility scenario. If fertility rates in the coming decades are lower than the "medium scenario" estimate, the share of elderly in the population will rise even further. Exhibit 2 shows how this source of uncertainty leads to differing predictions regarding the elderly share. The variation in 2050 represents more than one-fourth of the medium-scenario elderly share. This is not a huge range; however, the uncertainty regarding future fertility rate is coupled with the uncertainly introduced by the

\footnotetext{
${ }^{2}$ For a detailed analysis of several measures of population aging, see (Lutz, Sanderson and Scherbov, 2008)
} 
change over time in UN estimates of the future size of the elderly population (which are mostly driven by mortality estimates).

Exhibit 2 - Share of population that is at least 60 years old, by UN fertility assumption

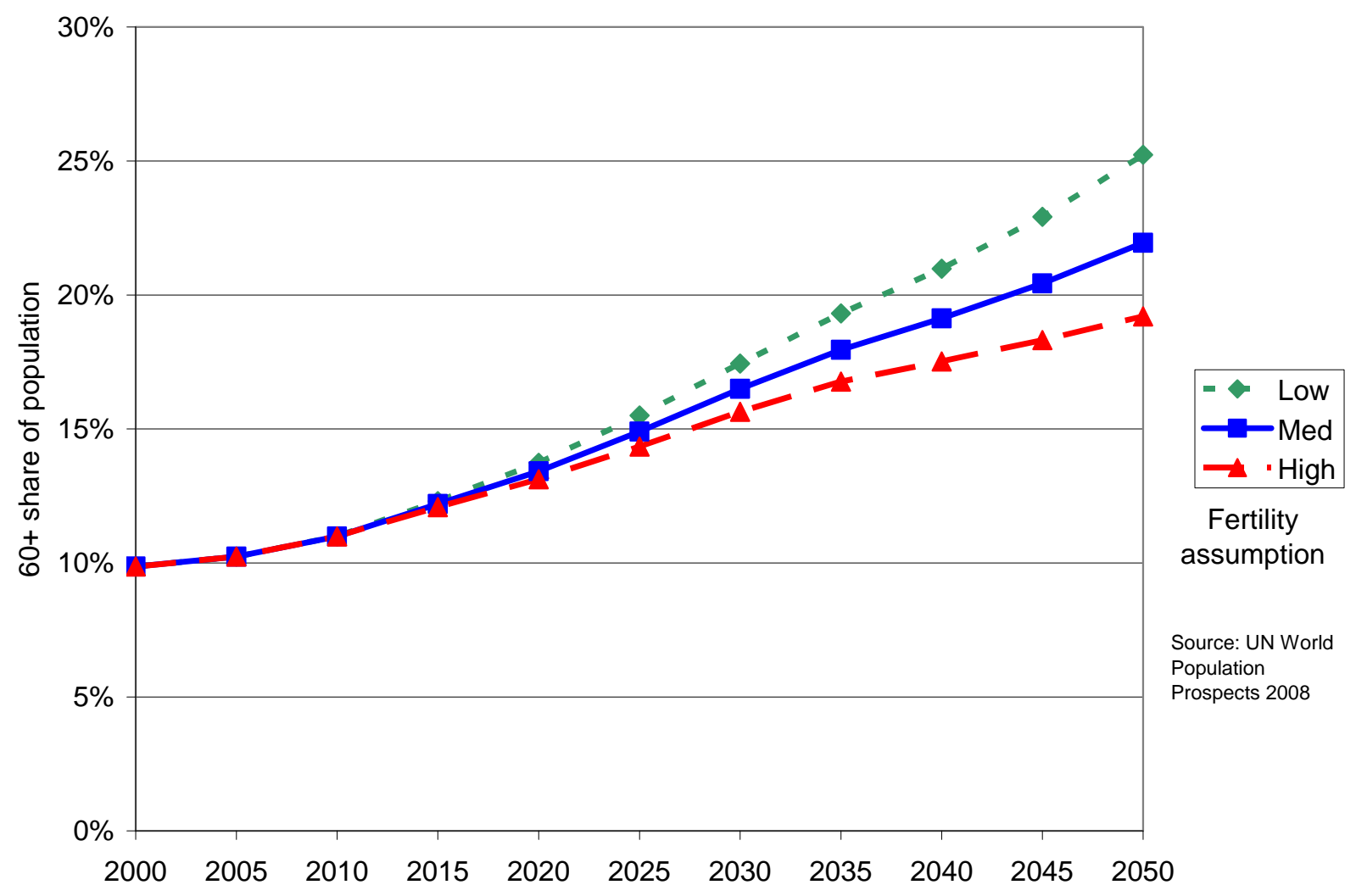

The phenomenon of population aging, of course, is not uniform across countries, and varies between developed and the developing countries (see Exhibit 3) and across regions (see Exhibit 4). 
Exhibit 3 - World and development-group age structure changes

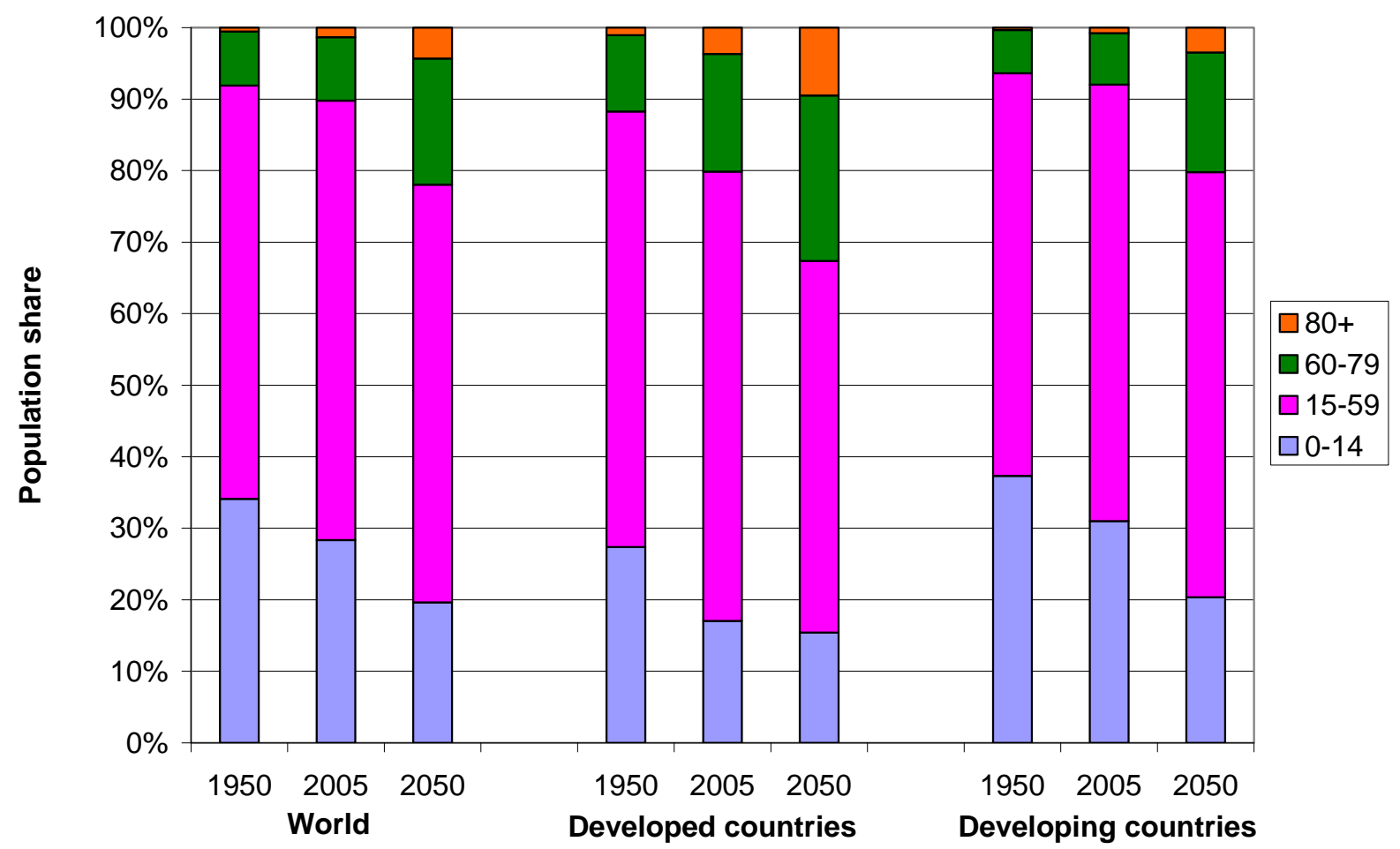

Source: Authors' calculations based on data in United Nations, World Population Prospects: the 2008 Revision 
Exhibit 4 - Share of 60+ population by region

Population share, $60+$, by region

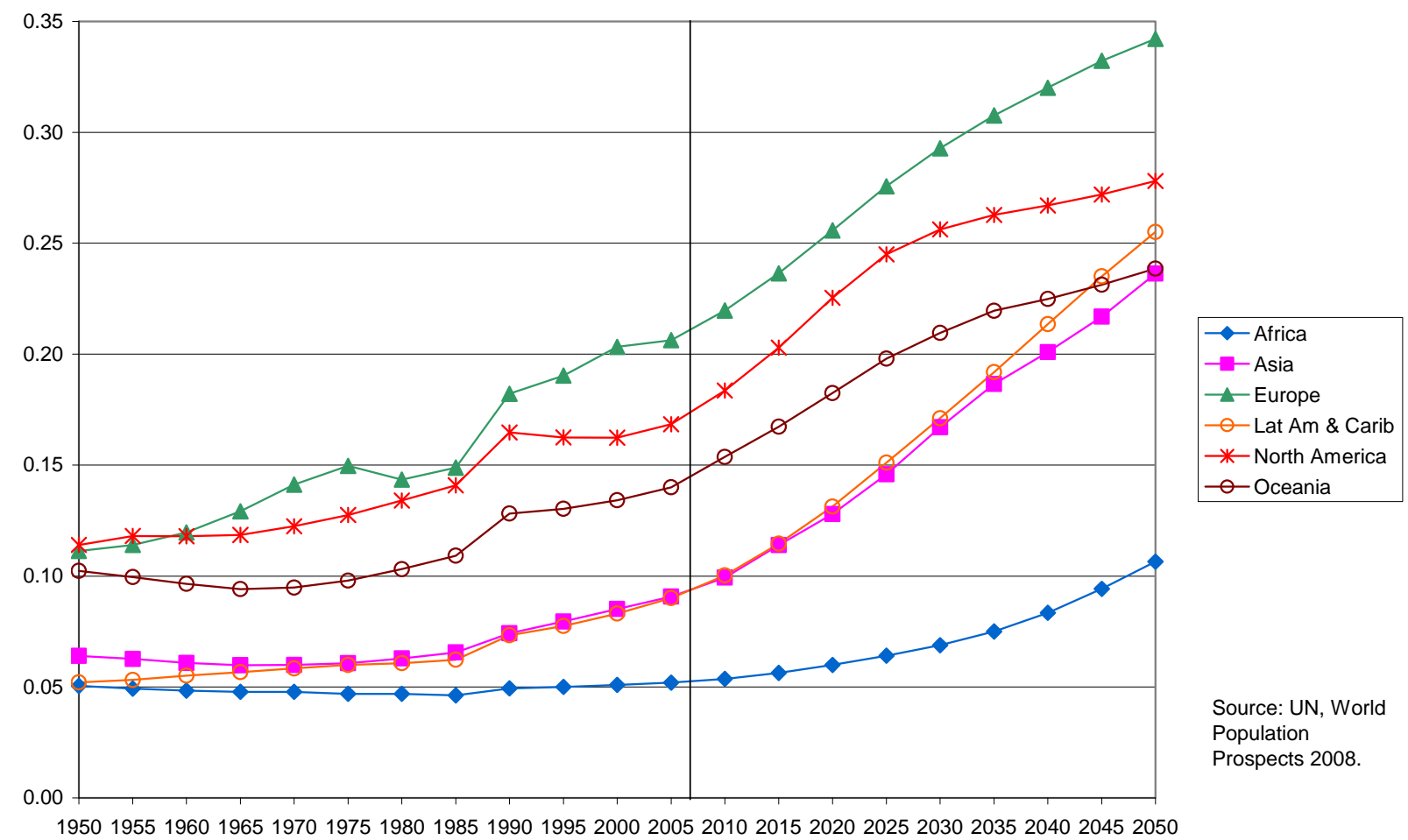

Most developing countries already have large elderly cohorts today. 20 per cent of the population of developed countries is aged over 60 today, and according to current forecasts this proportion will rise to over 30 per cent in the next four decades. In the developing world, less than 10 per cent of the population is aged over 60 , but this will soon change: by 2050 , the proportion is expected to more than double; the 60+ age group will make up 20 per cent of India's population and 31 per cent of China's by the middle of this century and constitute a total of over 750 million people.

\section{The drivers of aging}

There are three main factors behind these past and projected increases in the share of the global population aged $60+$ and $80+$. First, declining fertility rates in recent decades have reduced the relative number of young people and pushed up the share of the elderly. The global total fertility rate fell from approximately 5 children per woman in 1950 to just over 2.5 in 2005, and the UN projects that it will fall to 2 children per woman by 2050 (United Nations, 2009). Most of this decline has occurred in the developing world; this will contribute to a near halving of the share of children in the population of developing countries between 1965 and $2050 .^{3}$

\footnotetext{
${ }^{3}$ In some countries, fertility decline has led to pronatalist policies, which, if successful, would help to reverse the rise in the elderly share of the population. This effect notwithstanding, increased fertility would not begin to address
} 
The second key factor relates to recent increases in life expectancy. We calculate, for example, that one-fifth of the rise in India's 60+ population projected between 2000 and 2050 is due to rising life expectancy during that period; the corresponding figure for China is one-seventh. ${ }^{4}$ Global life expectancy has increased from 47 years in 1950 to over 65 today, and it is projected to reach 75 years by $2050 .^{5}$ Developed and developing countries alike are experiencing rises in life expectancy, despite HIV/AIDS reversing the trend in some low- and middle-income countries (Exhibit 5). As higher numbers of people survive into their 60s and beyond, the absolute number of elderly will soar. Combined with fertility declines, this results in a sharp increase in the share of elderly in the overall population.

\section{Exhibit 5 - Life expectancy, by level of development}

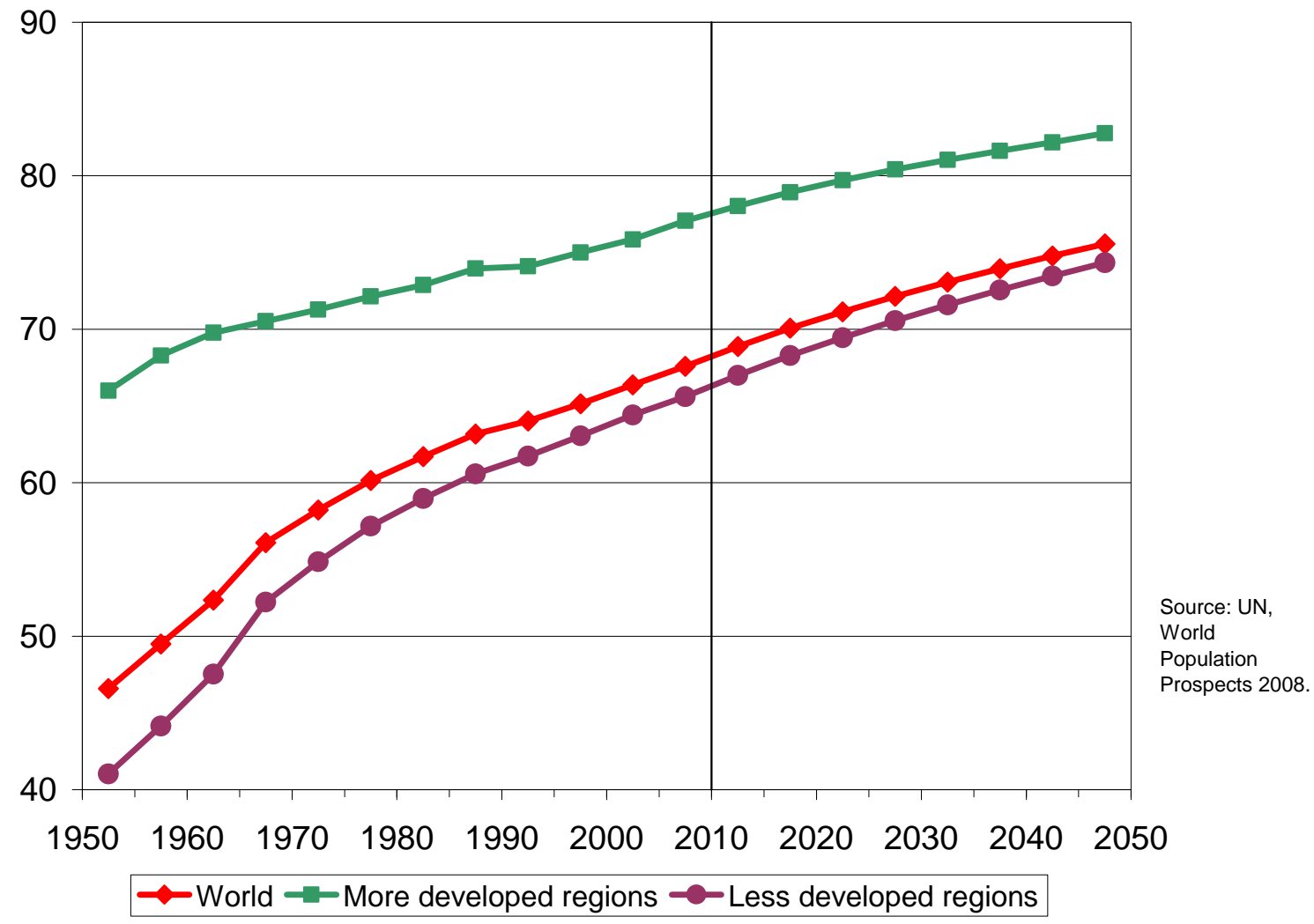

another concern about population aging - the decline in the working-age share - until about 20 years have passed, and a significant rise in that share would take even longer. See Bloom, Canning, Fink, and Finlay (2010) for an analysis of the short- and long-term impacts of fertility levels on working-age share.

${ }^{4}$ This calculation was made by comparing projections of India's population and age distribution from 2000 to 2050 using (a) linearly interpolated values of the UN Population Division's assumptions of the TFR and life expectancy in 2000 and 2050, and (b) linearly interpolated values of the UN Population Division's assumptions of the TFR with life expectancy held constant at its 2000 level. A similar calculation was made for China, except that life expectancy for women was fixed at 80 beyond the year 2035, due to a restriction imposed by the software package DemProj.

${ }^{5}$ UN Population Division (2009). 
The third factor behind population aging relates to past variations in birth and death rates. For example, baby booms resulting from increased fertility in rich countries after World War II are now shifting population structure as the cohort of boomers passes the age of 60. In parts of the developing world as well, some particularly large cohorts resulting from sustained high fertility rates in the presence of rapidly declining child mortality are now moving towards the $60+$ age range, substantially altering population age structure.

\section{Policy implications}

The aging of the world's population introduces several major policy challenges, and its unprecedented nature means that we cannot look to earlier historical episodes for guidance on how this demographic upheaval will unfold or on how best to manage it. On the other hand, population aging in most countries will not be noticeable for another decade or two: as the charts above show, the most rapid increase in aging has not yet occurred. This grants policymakers a window of opportunity in which to prepare for this change. Initiating action early can better prepare countries to deal with the social, economic, and political effects of an impending altered population structure.

People aged 60 or above usually have different needs and behaviors than younger individuals. Older individuals tend to work and save less, meaning that they offer less labor and capital to economies. They also require more health care and, in many countries, rely on social pensions for a large part of their income. As older populations become larger and politically stronger, adopting certain policies (such as cutting health and pension benefits) will prove difficult.

Those aged 80 or over also have different needs. With declining health the need for full-time care increases. In many cases, this also increases the need for financial support, as private savings tend to vanish rapidly for individuals with particularly long lifespans. As their numbers increase, they place further demands on government resources, familial resources, and personal savings. ${ }^{6}$

An intolerable strain on societies and economies imposed by a greater elderly share is not inevitable, however. Increased life expectancy has historically been strongly associated with increased per-capita income (Preston, 1975). Changes in age-specific health profiles are important for characterizing the phenomenon of population aging. If people advancing into their $60 \mathrm{~s}$ and $70 \mathrm{~s}$ are healthier than preceding generations, the demands for health care will be less intense and many will be able to work and contribute to their economies for longer (Kulish, Smith and Kent, 2006). If they remain no healthier than earlier cohorts, on the other hand, they will have to endure more years of poor health and will burden their societies with additional years of health care costs. Studies on whether increased life expectancy is accompanied by a compression of morbidity, where the relative or absolute length of life spent in chronic ill-health falls, have mainly focused on the United States. Most studies suggest that compression of morbidity has indeed occurred, meaning that the burden of aging is not as large as anticipated (Fries, 1980).

\footnotetext{
${ }^{6}$ That said, the degree to which healthcare costs increase depends on the system of healthcare provision and financing a country chooses. Neither developed nor developing countries need to adopt the policies and practices that have led to very rapid cost increases in the United States.
} 
Sanderson and Scherbov (2010) expand on this point by defining two indicators that make possible a more nuanced analysis of the future burden of aging populations: prospective old age dependency ratio, "the number of people in age groups with life expectancies of 15 or fewer years, divided by the number of people at least 20 years old in age groups with life expectancies greater than 15 years", and adult disability dependency ratio, "the number of adults at least 20 years old with disabilities, divided by the number of adults at least 20 years without them". Both of these indicators grow much more slowly than the old-age dependency ratio. Analysis of the economic consequences of aging that uses these indicators might reveal a smaller effect of aging on economic growth than appears in this paper. At least two factors, however, would limit the extent of the change such an analysis might reveal. First, people are not, in general, working to later ages; they are simply spending more time in retirement, as discussed immediately below. Second, the dramatic rise in prevalence of obesity, including among the elderly, also serves to limit the extent to which older people, despite being on average healthier than in the past, will work productively. Dor et al (2010) find that obesity imposes enormous financial costs on individuals, businesses, and the public (an average of \$4,879 annually for a woman and \$2,646 for a man). Employers face increased costs that stem from absenteeism, lower productivity, and direct financial outlays to cover medical care and disability. ${ }^{7}$

However, economies can respond to longer lifespans. Providing people more options with respect to the timing of retirement is one option. Our research on male life expectancy in 43 countries ${ }^{8}$ between 1965 and 2005 (Exhibit 6) shows an average rise of nearly nine years; for the same period, the mean legal retirement age rose by less than half a year. The correlation between male life expectancy and male retirement age in 1965 and 2005 is only 0.39 and 0.37 , respectively (and it would be even lower if not for a few outliers in our sample).

\footnotetext{
${ }^{7}$ Sanderson and Scherbov (2008) provide a detailed explanation of the concept and usefulness of "prospective age", based on remaining life expectancy. Because people are much healthier and more active at a given age than were their counterparts several decades ago, decisions about retirement, for example, take place in a different personal environment than previously. The authors point out that in studying the effects of an aging population, "Using prospective age instead of chronological age is a way to implement a population-based concept of old age that takes into account improvements in health and life expectancy." Consistent with the new indicators they define in Sanderson and Scherbov (2010), they define "old age" as the age above which remaining life expectancy is 15 years or less. They show that the set of countries that are the "oldest" depends critically on the old-age dependency ratio that is used: the conventional one, or one based on expected remaining life expectancy. Japan, for example, does not appear in the list of the 10 oldest countries, either in 2005 or 2045, when the prospective old-age dependency ratio is the criterion. Taking changes in life expectancy into account also has actuarial implications for pension system design. If obesity lowers the expected life expectancy of older individuals, the neutral response would be for a system to lower the retirement age.

${ }^{8}$ The sample includes all countries for which all data are available: mostly developed countries, with some middleincome and one very poor country included.
} 
Exhibit 6 - Changes in male life expectancy and retirement age, 1965-2005

\begin{tabular}{|l|c|c|c|}
\hline & 1965 & 2005 & Increase \\
\hline $\begin{array}{l}\text { Male life expectancy, } \\
\text { average }\end{array}$ & 64.7 & 73.4 & 8.8 \\
\hline $\begin{array}{l}\text { Male retirement age, } \\
\text { average }\end{array}$ & 62.9 & 63.3 & 0.4 \\
\hline
\end{tabular}

Source: World Bank (2007) for life expectancy. Social Security Administration, United States (2010) for retirement age.

More important, perhaps, is that the correlation between the change in male life expectancy and the change in retirement age between 1965 and 2005 is actually negative at -0.21 (see Exhibit 7). As people live longer, one might expect retirement age to increase, but on average this is not observable in the data currently available. Indeed, Exhibit 6 shows that the difference between life expectancy and retirement age increased from about 2 years in 1965 to about 10 years in 2005. There are some noticeable recent changes towards later retirement, nevertheless. The average actual age of retirement in the EU-27 rose from 59.9 to 61.4 between 2001 and 2008. Similarly, the statutory retirement age is set to increase in several EU countries by 2020, with further increases planned by most others after that. There is also some movement toward equalizing the statutory retirement age for men and women. (European Commission, 2010). Euobserver.com (2010) reports that the European Commission is suggesting a novel way of determining retirement age: it should be set, and raised on a regular basis, such that "not more than one third of adult life is spent in retirement." However, raising the retirement age has run into significant resistance in the past. Most Europeans have had expectations of a particular retirement age for many years and do not look kindly on the need to work longer than they had been anticipating. In addition, those who have made contributions to a retirement system feel particularly cheated, as they believed that their retirement age was set. Finally, even young workers have grown up with an understanding that retirement at a certain age is a given; they do not want to be the first ones to have to work longer. In the face of such resistance, President Sarkozy of France, for example, has only hesitantly pushed forward with pension reforms. He recently succeeded in pushing through such reforms, but only in the face of widespread strikes by students and workers. As of now, social security systems in many countries create strong incentives for retirement between the ages of 60 and 65. Adjustments in tax and benefit policies could encourage, and capture the benefits of, prolonged careers. ${ }^{9}$

\footnotetext{
${ }^{9}$ In the United States, these issues are playing out in the context of political pressures to reform the Social Security system. Many have argued that demographic shifts undermine the sustainability of the system. However, Krugman (2010) highlights the estimates of the actuaries of the Social Security program, who predict that the trust fund will last until at least 2037 - and that it may last indefinitely. Krugman also draws attention to the possible increase in the share of GDP that Social Security will require - rising from $4.8 \%$ to $6 \%$ - and notes that this is "a significantly smaller increase than the rise in defense spending since 2001, which Washington certainly didn't consider a crisis".
} 
Exhibit 7 - Change in male life expectancy vs. change in male retirement age, 1965-2005

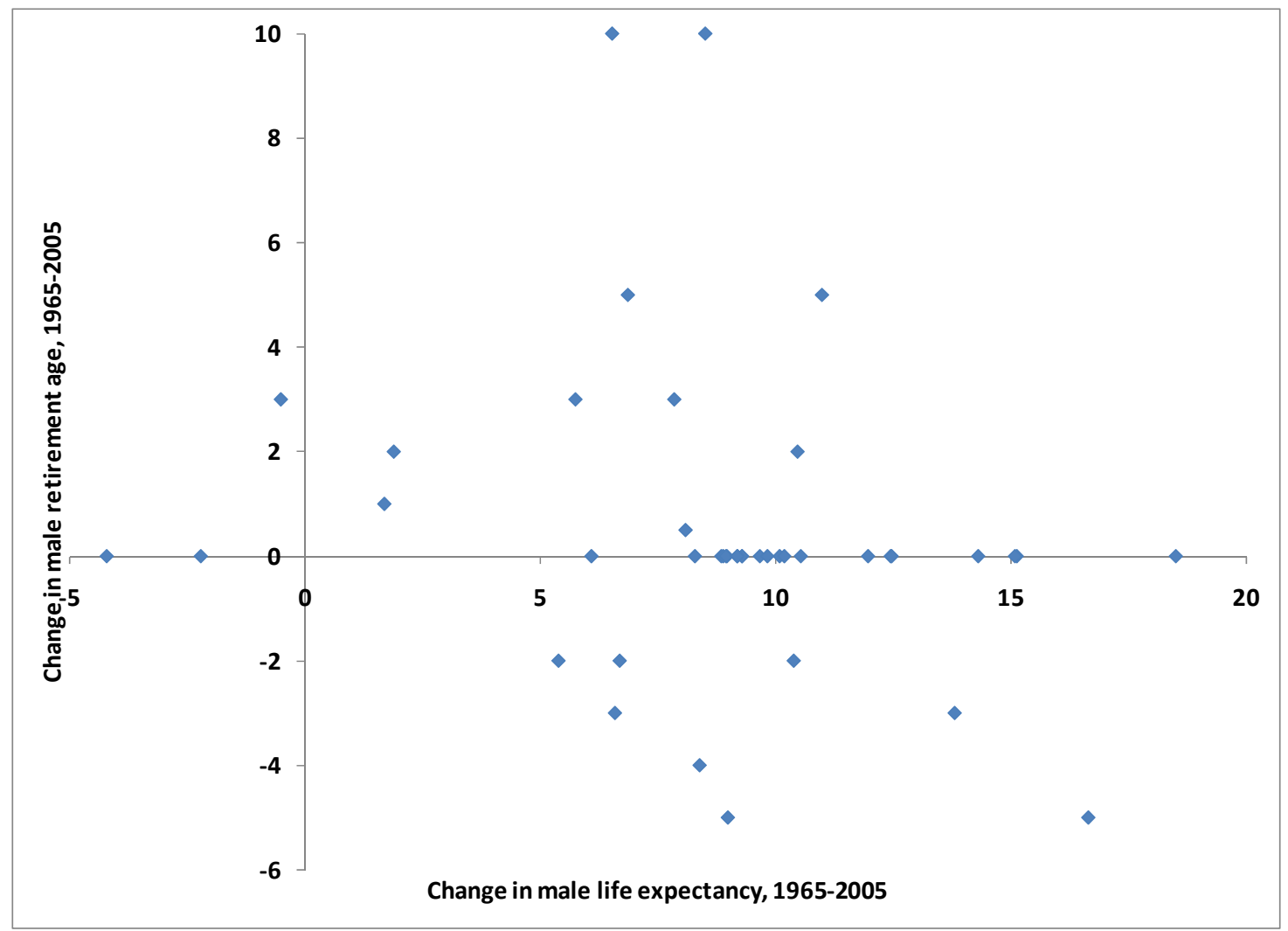

Source: World Bank (2007) for life expectancy. Social Security Administration, United States (2010) for retirement age.

Cross-country differences in the timing of the aging process may also mitigate the negative impacts of aging. Because rich countries are aging faster than poor ones, the former can draw on immigrant labor from the latter to compensate for the aging or retirement of their own citizens. The large cohorts of working-age people in developing countries, in turn, are likely to be interested in the vacancies created.

Migration from the developing to the developed world could therefore theoretically slow the latter's shift toward an aged population and ease the pressure on both sets of economies.

Migration, however, can bring with it social pressures and unrest, and many wealthy countries are already grappling with the difficult balance between the need for labor and the importance of dealing with immigration's social effects.

More broadly, an aging population will require increased support of various types, including income security and greater access to healthcare. While families have traditionally provided such support in many developing countries, increasingly this support is less reliable - particularly when women enter the workforce in larger numbers. Lower birthrates, the tendency of children to move away from their parents, widespread rural to urban migration, and new cultural norms regarding filial obligations are increasingly leaving the elderly bereft of the security they once had. 
Most countries have adopted at least some types of social protection plans to offer some level of income security and access to health care to those who need it, including the elderly. But as the elderly share of the population rises, protecting the elderly is likely to prove a challenge for governments when even those of working age are finding it difficult to make ends meet. Bloom, Mahal, Rosenberg, and Sevilla (2010b) explore this issue in the case of the developing countries of Asia and conclude that, in general, despite the difficulties, governments can afford to carry out more-extensive social protection programs, and that in doing so they will spur economic growth in a manner that is inclusive of those who most need to benefit from it. The International Labor Organization (2008) also investigates the question of affordability by studying a selected set of low-income countries in Africa and Asia. Its inquiry stresses "the need to ensure that global competition does not drive countries and their populations below agreed minimum labour and social standards, and to obtain international support in financing provisions of minimum basic social protection in low-income countries" until countries can carry out such programs on their own. The ILO tunes its assumptions to the circumstances of each country. In the case of a basic old-age pension, for example, a beneficiary would receive $30 \%$ of GDP per capita each year, with a dollar-per-day (but inflation-adjusted) cap. The ILO concludes that the studied countries could provide universal basic old-age and disability pensions by spending between 0.6 and 1.5 per cent of GDP each year. It also concludes that an expenditure of about $6 \%$ of GDP would make possible a basic set of social protection measures (i.e., including ones that go well beyond protection of the elderly). However, the ILO finds that, even under the assumption that countries can increase their social protection spending to $20 \%$ of the national budget, domestic resources alone will be insufficient, in the case of more than half of the countries studied, to cover the basic set of social protection measures (with the shortfall needing to be filled by international aid).

In the next section of the paper, we examine more closely some of the impacts of aging discussed above and in particular their implications for economic growth.

\section{The Economic Impacts of Population Aging}

\section{The importance of age structure}

Models and perspectives on the determinants of economic growth are plentiful in the academic literature. Some frameworks highlight the importance of improved productivity within all sectors, and the need for sectoral shifts, i.e., the reallocation of labor from the low productivity agricultural sector to the higher productivity industry and service sectors. . Others emphasize the contribution to growth of technological progress, human capital, institutions and governance, macroeconomic and trade policies, and random shocks. Still others stress feedback effects that run from economic growth to technical progress and human capital accumulation, which in turn influence economic growth. ${ }^{10}$

\footnotetext{
${ }^{10}$ Tyers and Shi (Tyers and Shi, 2007) introduce demographics (population size and its age, sex, and skill composition) into a dynamic computable general equilibrium model of the world economy with exogenouslydetermined age patterns of labor force participation, consumption, and savings. Their work indicates that accelerated population aging (via lower fertility) tends to enhance real per capita income growth in regions with very young populations and slows it in regions with older populations and low rates of labor force participation among the elderly (e.g., Western Europe). Based on a model that is similar in spirit, though demographically less fine-grained,
} 
The key premise of this paper is that changes in population age structure may exert a significant influence on economic growth. We adopt a life cycle perspective, based on the fact that people's economic needs and contributions vary over the various stages of life. Specifically, the ratio of consumption to production tends to be high for the youth and elderly and low for working-age adults. This means that key drivers of economic growth such as aggregate labor supply, productivity, consumption, and savings will tend to vary depending on where most people fall in the life cycle. Among these factors, it is well understood that labor supply and savings are higher among working-age adults than among those aged 60 or above. Other things equal, therefore, a country with large cohorts of youth and elderly is likely to experience slower growth than one with a high proportion of working-age people.

The value of this approach can be seen in an analysis of the impact of changing age structure on East Asia's remarkable economic growth in the second half of the $20^{\text {th }}$ century (Bloom and Williamson, 1998). Rapid declines in infant and child mortality in the region began in the late 1940s, and these declines triggered a subsequent fall in fertility rates: the crude birth rate dropped from over 40 births per 1,000 people in 1950 to just over 20 by 1980 . The lag between falling mortality and fertility created a "baby boom" generation, which was larger than the cohorts that preceded and followed it. As this generation reached working age, it boosted savings rates and also the size of the labor force; from 1965 to 1990, the working-age population grew by 2.4 per cent annually and the dependent population by just 0.8 per cent. Bloom and Williamson (1998), and Bloom, Canning, and Malaney (2000) estimate that this "demographic dividend" explains up to one-third of East Asia's economic miracle between 1965 and 1990. Bloom, Canning, and Sevilla (2003) provide a more extensive exposition of this phenomenon, while Bloom and Canning (2008) emphasize the importance of appropriate institutions and policies in bringing about the demographic dividend.

\section{Accounting effects}

If age-specific behavior with respect to labor supply and savings were fixed, labor supply and savings per capita would tend to decline with a rising elderly share of the population. Keeping all other factors such as productivity and migration equal, this would imply lower growth in income per capita. This frame of reference appears to underlie the rather alarmist views of commentators such as Peter Peterson, who has argued that, "global aging could trigger a crisis that engulfs the world economy [and] may even threaten democracy itself" (Peterson, 1999). Ken Dychtwald has also raised concerns that, "we're going to have a self-centered generation just sucking down all the resources"(Dychtwald, 1999), and former U.S. Federal Reserve Chairman Alan Greenspan has warned that aging in the United States "makes our social security and Medicare programs unsustainable in the long run"(Greenspan, 2003). ${ }^{11}$

McKibbin (McKibbin, 2006) reaches qualitatively similar conclusions, but also highlights the implications of global demographic change for international trade and capital flows and therefore for domestic economic performance.

${ }^{11}$ As noted in an earlier footnote, Paul Krugman has expressed a dim view of such concerns insofar as they apply to the Social Security system in the United States, because its critics misrepresent its financial stability and are motivated by concerns that go far beyond Social Security itself. 
The European Union's Economic Policy Committee (2010) is more measured in its assessment of the threat: "The ageing of the population is becoming a growing challenge to the sustainability of public finances in the EU Member States. The increase of the ratio between the number of retirees and the number of workers will amplify expenditure on public pensions and health and long-term care and thus puts a burden on maintaining a sound balance between future public expenditure and tax revenues." The World Economic Forum (2004) is concerned, but similarly cautious, suggesting that with large numbers of non-working elderly, "we face the prospect that the historical rates of improvement in standards of living might slow or even decline." Appropriately, the Forum's report goes on to stress the value of raising the retirement age and points out that both governments and businesses can play a role in encouraging workers to continue working.

To provide some sense of the extent of these demographic effects on labor supply and ultimately on economic growth, we compare demographic shifts that occurred between 1960 and 2005 to projected changes between 2005 and 2050, and investigate how economic growth between 1965 and 2005 would have looked under the alternative "future demographic change" scenario. We begin by assuming that labor force participation will remain constant, i.e., that women and men of a specified age group are equally likely to be active in the labor force in 2050 as they were in 2005. The ILO currently publishes male and female labor force participation rates for each 5year age group from age 15-19 to 60-64, as well as average participation rates for individuals aged 65 and older. Taking these age- and sex-specific participation rates as given, and combining them with official population projections numbers, we can calculate total labor force participation rate (LFPR), which is defined as the number of men and women active in the labor force divided by the total population aged 15 and older.

Population data are from the latest revision of World Population Prospects (United Nations, 2009). The results for the 171 countries where both labor force participation data from the ILO and population data are available over the period 1960-2005 are shown in Exhibits 8 and 9. In Exhibit 8, we plot actual LFPR in 2005 against actual labor force participation rate in 1960, while in Exhibit 9 we plot projected (age-structure-adjusted) labor force participation rates in 2050 against actual labor force participation rates in 2005.

The overall pattern emerging from Exhibit 8 is rather mixed, with no distinct trend over the period. The average LFPR was 0.65 both in 1960 and 2005, with 96 countries (56\%) displaying higher rates of labor force participation in 2005 than in 1960, and the opposite being true for 75 countries (44\%). These patterns reflect the beginning of the demographic transition in developing countries as well as the post-World War II baby booms in the developed countries. Exhibit 8 also reveals a certain degree of convergence or demographic cyclicality, as countries with exceptionally high LFPR in 1960 (countries on the right hand side of Exhibit 8) tend to have lower LFPR in 2005. 
Exhibit 8 - Labor force participation - 1960 versus 2005

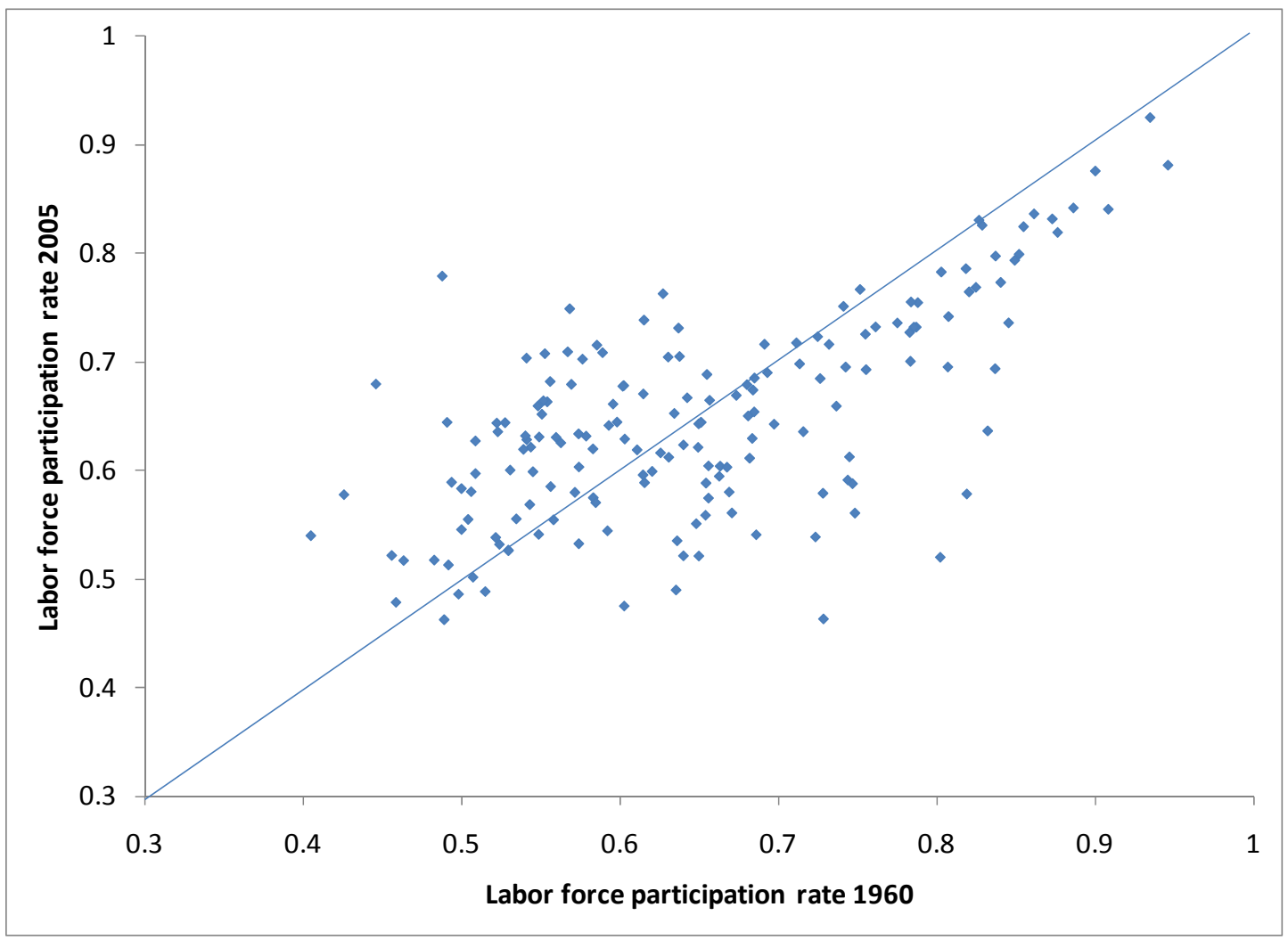

As Exhibit 9 shows, the picture looks very different when comparing 2005 actuals with projections for 2050. Our projections imply the LFPR will decline for about three quarters (126) of the countries analyzed with constant age- and sex-specific labor force participation rates. On average, LFPR is expected to fall from 0.66 to 0.61 . Compared with the variation across countries, this shift is relatively small, representing only about $50 \%$ of one standard deviation. The expected shifts are, however, sizeable for individual countries. LFPR is expected to decline from 0.75 to 0.62 in China, from 0.63 to 0.45 in Singapore, and from levels around 0.58 to 0.45 in Western European countries like Austria and Germany. 
Exhibit 9 - Labor force participation - 2005 actuals vs. 2050 projections

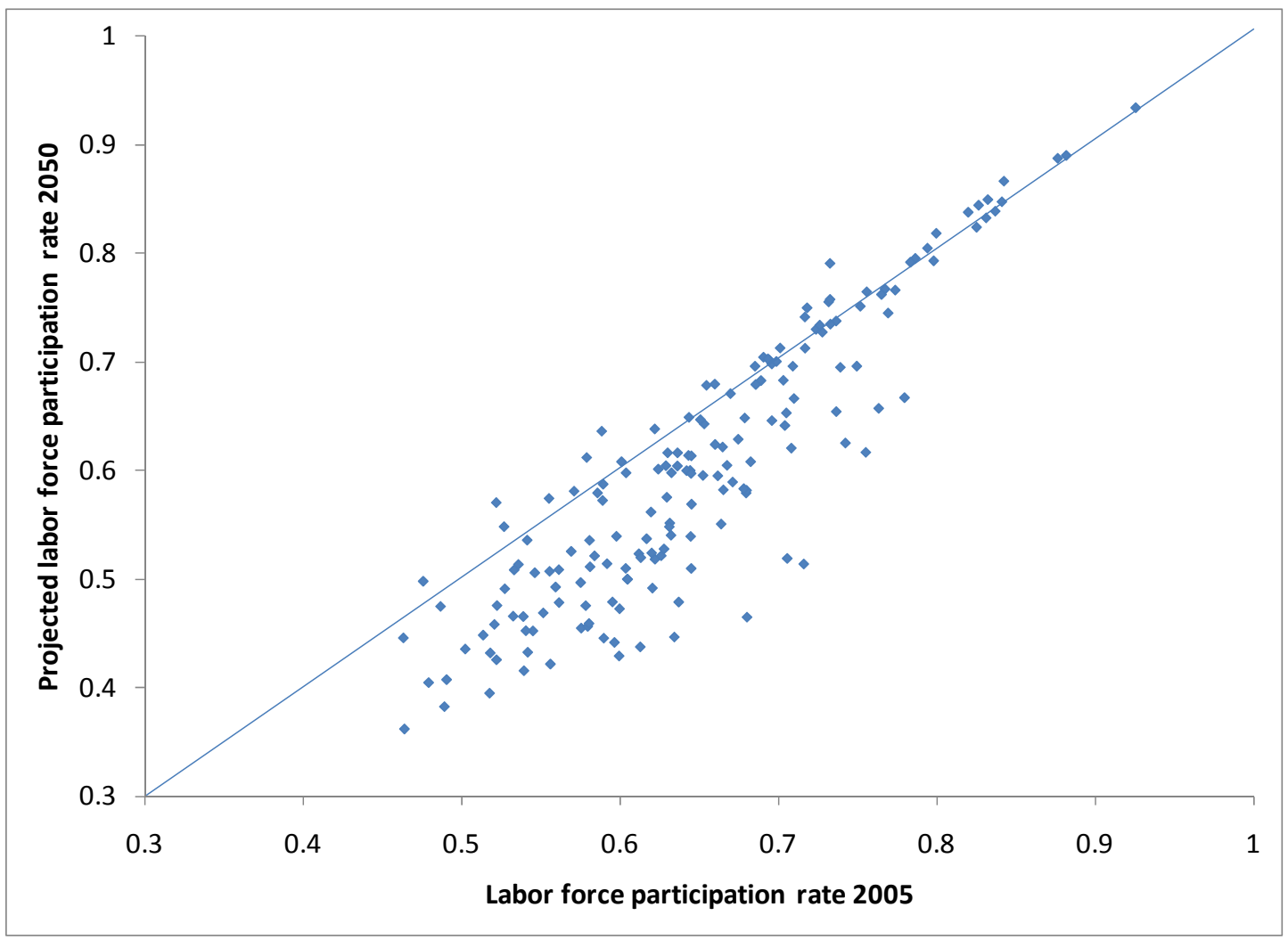

As Exhibits 10 and 11 show, these average declines in LFPR are, however, not matched by declines in the size of the labor force relative to the overall population. Due to the continued decline in fertility rates, youth dependency ratios are expected to fall in nearly all countries; this effect is large, and as illustrated in Exhibit 10, on average dominates the aging effect. Over the period 2005 to 2050 , the average number of workers per person is expected to increase from 0.47 to 0.49 . Out of the 171 countries analyzed, the LFTP is expected to decline only in 66 countries, while the LFTP is expected to increase in 105 countries, despite continued aging.

Exhibit 10: Global Labor Force: 1960, 2005, and 2050

\begin{tabular}{|lccc|}
\hline & 1960 Actual & 2005 Actual & 2050 Projected \\
LFPR (labor force/pop15 +) & 0.674 & 0.658 & 0.614 \\
LFTP (labor force/pop) & 0.423 & 0.471 & 0.490 \\
\hline
\end{tabular}

* 2050 projections are based on medium-fertility population projection and age- and gender-specific participation rates in 2005. All figures are population weighted. 
Exhibit 11 - Labor force-to-population ratio - 2005 vs. 2050

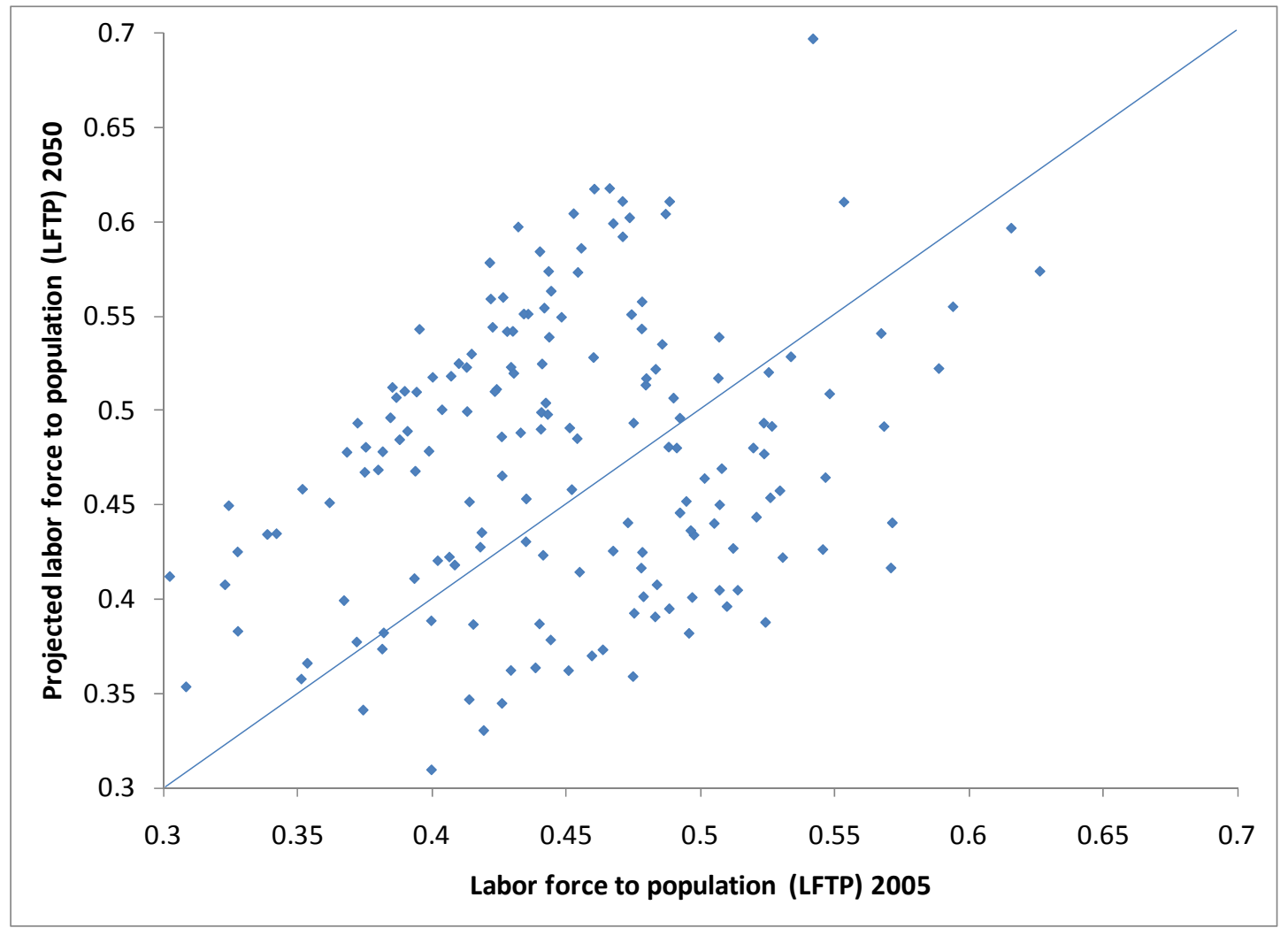

Note: 2050 projections are based on medium-fertility population projection and age- and gender-specific participation rates in 2005 .

To get a better sense of what these numbers imply for economic growth, we decompose total actual growth between 1960 and 2005 into growth in GDP per worker and growth in LFTP. Income per capita in any given period is defined as total GDP divided by population $(\mathrm{P})$, which implies that GDP per worker (W) is equal to income per capita divided by the number of workers per capita, i.e.,

$$
\frac{G D P}{W}=\frac{G D P / P}{W / P}=\frac{G D P / P}{L F T P}
$$

Taking logs, GDP per capita can be expressed as

$$
\ln \left(\frac{G D P}{W}\right)=\ln (G D P / P)-\ln (L F T P),
$$

so growth in real income per capita between period $\mathrm{t}$ and period $\mathrm{t}+1$ can be approximated by

$$
g_{t, t+1}=\left[\ln \left(G D P_{t+1} / W_{t+1}\right)+\ln \left(L F T P_{t+1}\right)\right]-\left[\ln \left(G D P_{t} / W_{t}\right)+\ln \left(L F T P_{t}\right)\right]
$$

This simplifies to 


$$
g_{t, t+1}=\ln \left(\frac{G D P_{t+1} / W_{t+1}}{G D P_{t} / W_{t}}\right)+\ln \left(\frac{L F T P_{t+1}}{L F T P_{t}}\right)
$$

and implies that growth in income per capita can be directly decomposed into growth in income per worker and growth in LFTP.

To grasp the size of the potential economic consequences of the change in LFTP growth rate, we conduct the following thought experiment. Assume that income per capita had followed its actual path between 1960 and $2005^{12}$, but that population and LFTP had undergone the change they are expected to undergo between 2005 and 2050, rather than the actual (and even more favorable, presumably) change they underwent during the period 1960-2005.

The results of this thought experiment are displayed in Exhibits 12 (all countries) and 13 (OECD only). Given the relatively long time horizon, income per capita data are missing for a large group of countries, so our remaining sample of 107 countries is significantly smaller than the sample used in the previous exercise.

Exhibit 12 - Actual and Counterfactual Annual Growth Rates of Income per Capita, 1960-2005 (counterfactual assumes 2005-2050 growth rate of labor force per capita)

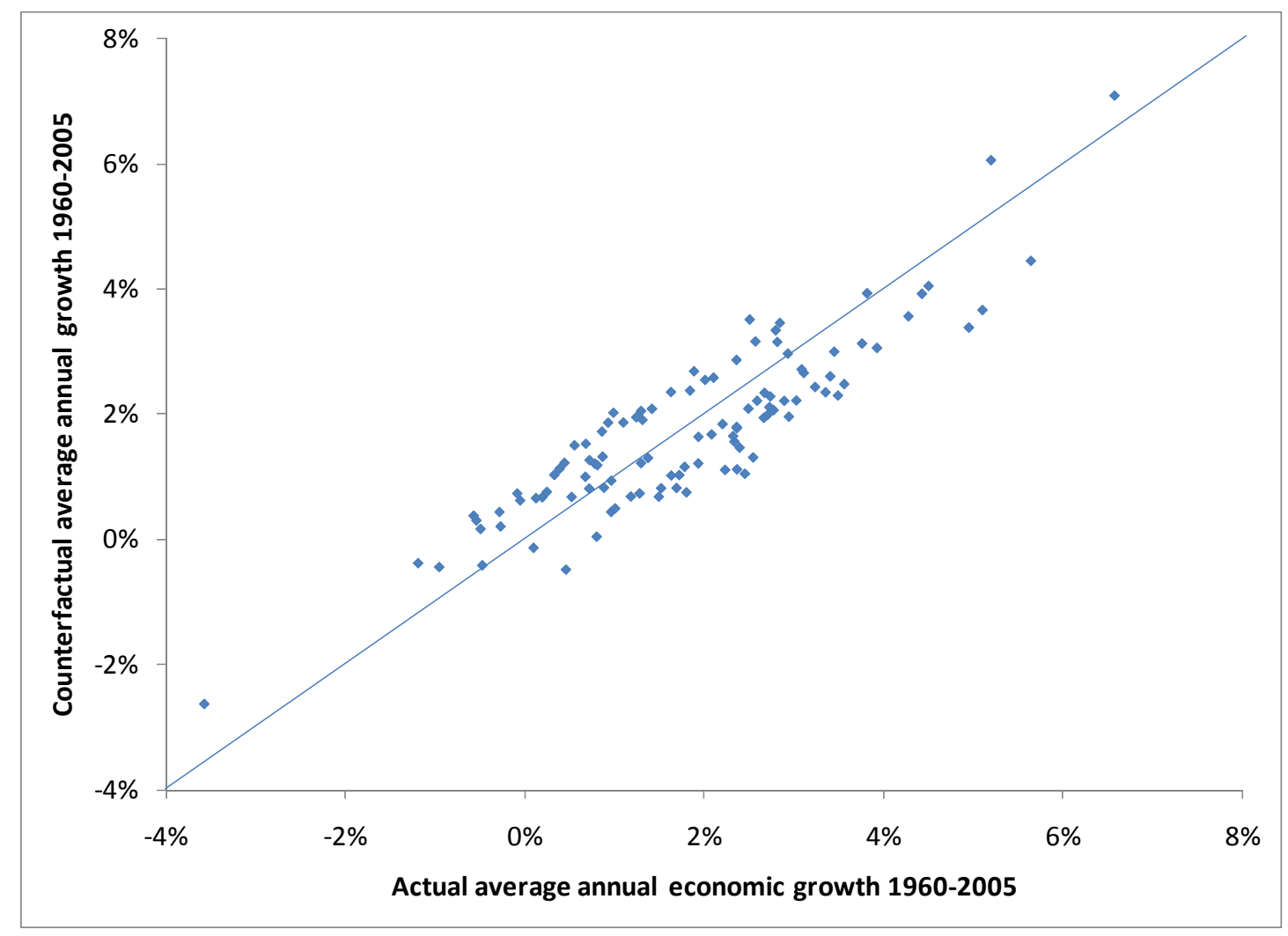

\footnotetext{
${ }^{12}$ Average growth in real GDP per worker was 1.5 percent per year, which is slightly less than the average annual growth in GDP per capita of 1.8 percent per year.
} 
The overall picture emerging from Exhibit 12 is quite balanced, with most countries scattered closely around the 45 degree line. Although the average actual growth rate was 1.84 percent per year over the period, our calculations imply that growth rates would have been 1.75 percent per year under the counterfactual assumption of the less favorable demographic environment anticipated for the period 2005 to 2050 . Out of the 107 countries analyzed, about half of the countries (58) would have grown more slowly under the counterfactual 2005-2050 demographic scenario. The two countries or areas with the largest difference between actual and counterfactual growth are Singapore and Hong Kong, with actual average annual growth rates close to 5 percent per year, and counterfactual growth rates of 3.4 and 3.7 percent per year, respectively. As Exhibit 13 illustrates, the picture looks similar for most OECD countries. With a much earlier onset of fertility declines, the period 1960-2005 brought favorable demographic change for most OECD countries, while substantial declines in LFTP are expected for the coming decades. With the notable exception of Turkey, all 26 OECD countries analyzed would have displayed lower economic growth under the counterfactual scenario. Our calculations imply that on average OECD countries would have grown by 2.1 rather than by 2.8 percentage points per year. The long-run developmental differences are substantial; a country with income per capita of US\$10,000 (OECD average in 1960) would have reached an income per capita of $\$ 25,500$ within a 45 -year period at the counterfactual growth rate of 2.1 percent per year, whereas a country with the actual growth rate of 2.8 percent per year would have achieved an income per capita of US\$ 34,600 over the same period.

Exhibit 13 - Current OECD Members Only: Actual and Counterfactual Annual Growth Rates of Income per Capita, 1960-2005 (counterfactual assumes 2005-2050 growth rate of labor force per capita)

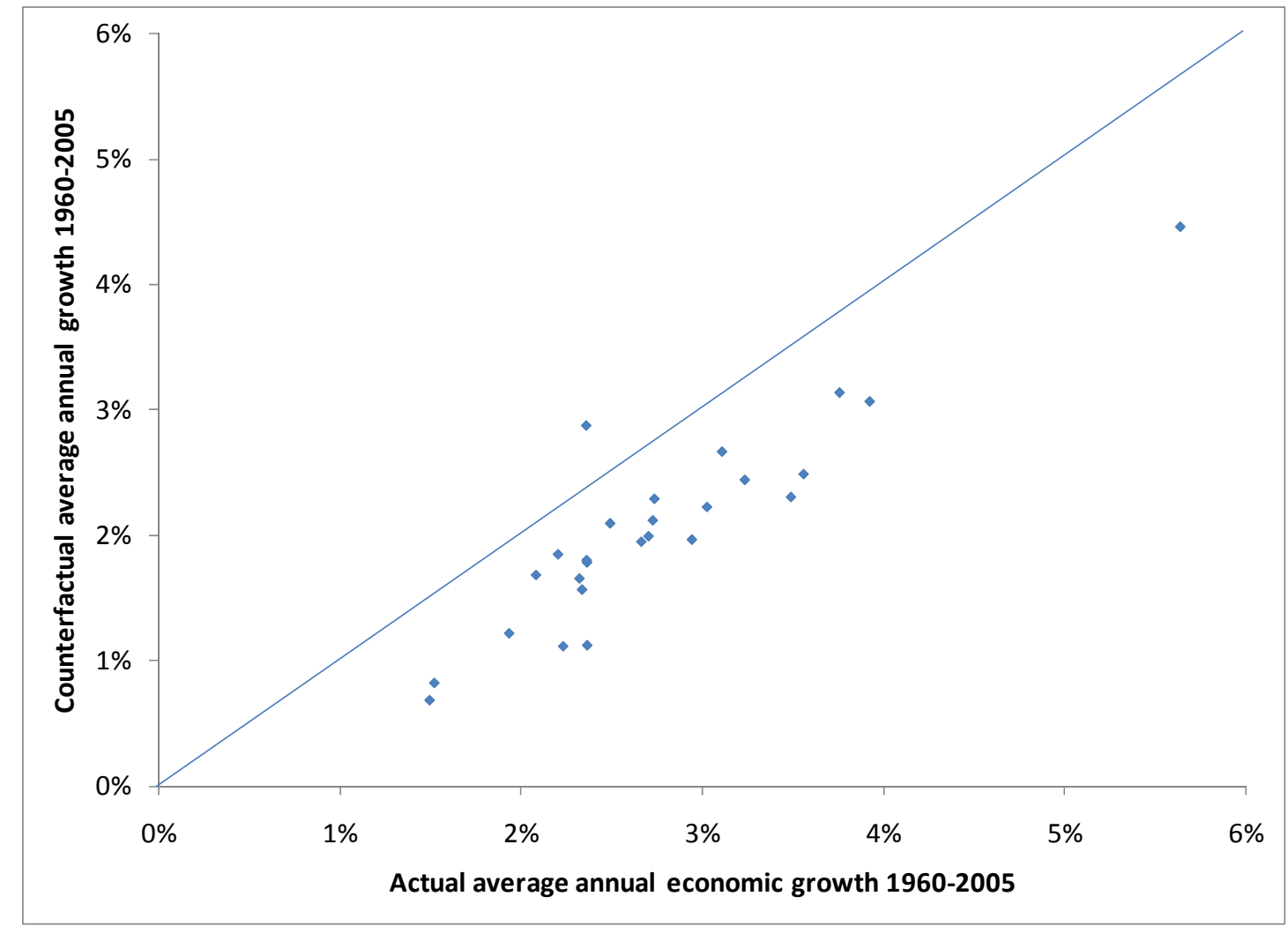


For most Sub-Saharan African countries, the picture is reversed; given the projected slowing of population growth and the expected declines in fertility between 2005 and 2050, most SubSaharan African countries would have fared significantly better under the counterfactual scenario, with an average difference of plus one percentage point per year for countries like Senegal, Uganda, Benin, and Burkina Faso. Our calculations imply that developing countries classified as low income in 2005 would have grown 0.67 percentage points faster over the 19602005 period under the counterfactual assumption, resulting in an average real income per capita of US\$ 2160 rather than the actual value of US\$ 1680 today.

\section{The role of behavior change}

All of the numbers presented in the previous section are likely over-estimates of the true effects of ageing as they neglect behavioral change in response to changing age structures and life expectancies. As family size and life expectancy change, individual behavior can be expected to change along several dimensions.

First, with better health and increased life expectancies, one can expect individuals to work longer. As shown in Bloom, Canning, Mansfield and Moore (2007), the theoretically optimal response to rising life expectancy is to increase the number of working years and the number of years in retirement proportionately, without changing period-specific saving behavior. In recent work by Kulish, Smith, and Kent (2006), this optimal response is also reflected in stated preferences: individuals surveyed in Australia expressed a desire to spend a similar proportion of their lives in retirement as life expectancy increases. However, this theoretical response and general preference have not yet translated into real increases in old-age labor force participation; if anything, participation among the 60+ age groups has decreased, rather than increased, in most OECD countries despite the substantial improvements in life expectancy over the last decades.

While a large set of factors - such as increasing demand for leisure, general increases in wealth, and difficult labor markets - have contributed to low labor force participation among the elderly, social security systems have undoubtedly been a key reason for the continued low or falling labor force participation among the elderly. As shown in Gruber and Wise (1998), most social security programs feature several direct or indirect incentives for individuals to retire early rather than continue working. In some countries, retirement is mandatory in order to receive pension benefits; in others, pension rates are kept flat or adjusted in a way that is not actuarially fair, so additional years of contribution are given only partial credit, or no credit at all. In all countries analyzed by Gruber and Wise, retirement incentives and behavioral responses are large. The large spike in retirement at age 62 in the United States (the earliest age at which Social Security benefits can be claimed) and another spike at age 65 (an age at which new retirees have access to even larger benefits) are good examples of this (Burtless and Moffitt, 1985). Bloom, Canning, Fink, and Finlay (2007) show that similar results hold for a larger set of countries, with pension systems lowering old-age labor force participation by up to 20 percentage points.

Second, even if individuals decide to not work longer, increased life expectancies can be expected to induce increased savings over the working life in order to finance a continued high 
standard of life in retirement. This claim is empirically supported by Bloom, Canning, and Graham (2003) who find that that increased life expectancy is generally also associated with higher savings rates. Bloom, Canning, Mansfield, and Moore (2007) find that savings rates increase with life expectancy in countries with universal pension coverage and retirement incentives, but not in countries with pay-as-you-go systems and high replacement rates.

A third mechanism through which societies respond to longer life expectancies and smaller family sizes is increased labor force participation. As the number of children per woman declines, more women enter the labor force. Bloom, Canning, Fink, and Finlay (2009) estimate the average female labor force participation response to reduced fertility in a cross-country panel study. As shown in Exhibit 14, declines in labor force participation are substantial across the fertile years, with each unit increase in TFR leading to a decrease in labor force participation of between 5 and 10 percentage points.

Exhibit 14 - Change in female labor force participation rates per unit increase in TFR

\section{Percentage point change in female labor force participation per unit increase in TFR}

Age group

Change in age-group-specific female labor force participation (percentage points)

\begin{tabular}{ccccc}
$\mathbf{2 0}-\mathbf{2 4}$ & $\mathbf{2 5 - 2 9}$ & $\mathbf{3 0 - 3 4}$ & $\mathbf{3 5}-\mathbf{3 9}$ & $\mathbf{4 0 - 4 4}$ \\
\hline-6.2 & -5.2 & -8.1 & -9.2 & -8.7 \\
$(3.40)$ & $(2.96)$ & $(3.48)$ & $(4.01)$ & $(4.28)$
\end{tabular}

Numbers in parentheses are standard errors.

Source: Bloom, Canning, Fink, and Finlay (2009), Table 8.

Given that current population projections predict substantial declines in total fertility rates between 2005 and 2050, sizeable increases in female labor force participation should be expected over the next decades. To see how these changes in labor force participation affect the size of the labor force and economic growth, we repeat the simulations displayed in Exhibit 10 taking changing female labor force participation behavior into account. As in Exhibit 10, we assume that age- and gender-specific participation rates are constant at their 2005 levels for males, and compute female labor force size both with and without behavioral adjustment. Since the magnitude of the behavioral adjustment depends on the expected TFR levels, we perform these calculations for the low-, medium-, and high-fertility scenarios published in World Population Prospects (United Nations, 2009).

Exhibit 15 shows the results for the sample of 180 countries where 2005 labor force participation rates as well as population projections are available. The first row of the table shows female and total LFTP for 2005. The second block of the table shows female and total LFTP for the three fertility scenarios under the assumptions that both male and female labor force participation rates stay the same; the third block shows the results for the counterfactual assumption that male labor force participation rates stay the same, and female labor force participation adjust to changing fertility rates as shown in Exhibit 14. On average, LFTP is expected to increase from 0.47 to 0.49 under the medium-fertility scenario; under the high-fertility scenario, LFTP is expected to 
slightly decline, while the increases in LFTP are slightly larger under the low-fertility scenario than under the medium fertility scenario we used as baseline assumption in Exhibit 10. In terms of annual economic growth, these effects are moderate. Over the 45-year period from 2005-2050, our results suggest that the average increase in economic growth generated by changing age structure is about 0.1 percentage points per year; taking female labor supply response into account, the outlook becomes slightly more favorable, with an estimated increase of 0.15 percentage points of annual growth per year in the medium-fertility scenario, and as much as 0.27 percentage points in the low-fertility scenario.

Exhibit 15 - Labor force-to-population ratios 2005 and 2050 with and without female labor supply response

\begin{tabular}{lccc}
\hline \hline & $\begin{array}{c}\text { Labor force per } \\
\text { capita, females }\end{array}$ & $\begin{array}{c}\text { Labor force per } \\
\text { capita, males } \\
\text { and females }\end{array}$ & $\begin{array}{c}\text { Change in annual } \\
\text { economic growth, } \\
\text { percentage points }\end{array}$ \\
\cline { 2 - 4 } Actual 2005 & 0.379 & 0.471 & \\
No behavioral change & & & \\
& & & 0.19 \\
Predicted 2050: Low fertility scenario & 0.379 & 0.512 & 0.09 \\
Predicted 2050: Medium fertility scenario & 0.366 & 0.490 & -0.01 \\
Predicted 2050: High fertility scenario & 0.352 & 0.467 & \\
& & & 0.27 \\
Female labor supply response & & & 0.15 \\
Predicted 2050: Low fertility scenario & 0.419 & 0.532 & 0.02 \\
Predicted 2050: Medium fertility scenario & 0.395 & 0.504 & \\
Predicted 2050: High fertility scenario & 0.369 & 0.476 & \\
\hline \hline
\end{tabular}

Notes: Based on 180 countries. All averages are population weighted.

Sources: ILO (2009) and World Population Prospects 2008 (United Nations, 2009)

As shown in Exhibit 16, these numbers look less favorable for the OECD countries. On average, our calculations suggest that LFTP will decline from 0.48 in 2005 to between 0.43 and 0.45 in 2050 , implying a negative growth effect of -0.16 to -0.28 percentage points per year. Given that total fertility rates have already converged to below-replacement levels in most OECD countries, the numbers do not change very much once the female labor supply response is taken into account. 
Exhibit 16 - Labor force-to-population ratios 2005 and 2050 with and without female labor supply response: OECD countries only

\begin{tabular}{lccc}
\hline \hline & $\begin{array}{c}\text { Labor force per } \\
\text { capita, females }\end{array}$ & $\begin{array}{c}\text { Labor force per } \\
\text { capita, males } \\
\text { and females }\end{array}$ & $\begin{array}{c}\text { Change in annual } \\
\text { economic growth, } \\
\text { percentage points }\end{array}$ \\
\cline { 2 - 4 } Actual 2005 & 0.407 & 0.484 & \\
No behavioral change & & & \\
Predicted 2050: Low fertility scenario & 0.364 & 0.450 & -0.16 \\
Predicted 2050: Medium fertility scenario & 0.358 & 0.440 & -0.21 \\
Predicted 2050: High fertility scenario & 0.350 & 0.427 & -0.28 \\
& & & \\
Female labor supply response & & & -0.14 \\
Predicted 2050: Low fertility scenario & 0.375 & 0.455 & -0.21 \\
Predicted 2050: Medium fertility scenario & 0.359 & 0.440 & -0.31 \\
Predicted 2050: High fertility scenario & 0.340 & 0.422 & \\
\hline \hline
\end{tabular}

Notes: Based on 32 current OECD member countries. All averages are population weighted.

Sources: ILO (2009) and World Population Prospects 2008 (United Nations, 2009)

In some countries, the labor force participation may grow because large, unemployed or underemployed working-age populations could be drawn into the labor market if population aging threatens to cause labor shortages. Banister, Bloom, and Rosenberg (2010) explore the case of China, where millions of rural residents, unable to find work in the countryside, have moved to the cities. Despite this migration, millions of workers in both rural and urban areas are still unemployed or have only marginal employment. Although less-employed workers in China, in general, have had less education than employed Chinese and will no doubt be harder to integrate into the labor force than those who are already working, the authors point out that market forces will tend to pull this dormant segment of the labor force into employment when employers need more workers. Underemployed workers who already reside in cities are obvious candidates for absorption into China's burgeoning manufacturing sector. Exhibit 17 shows that both male and female workers saw substantial drops in labor market participation between 1990 and 2005, suggesting that increased demand for labor stemming from the retirement of large cohorts of older workers could result in a return to higher labor force participation rates. Underemployed rural workers, too, may be further spurred to move to cities if the government takes additional steps to mechanize agriculture and further reduces controls on internal migration. 
Exhibit 17: City Employment Participation in China, 1990 and 2005, by Age and Sex

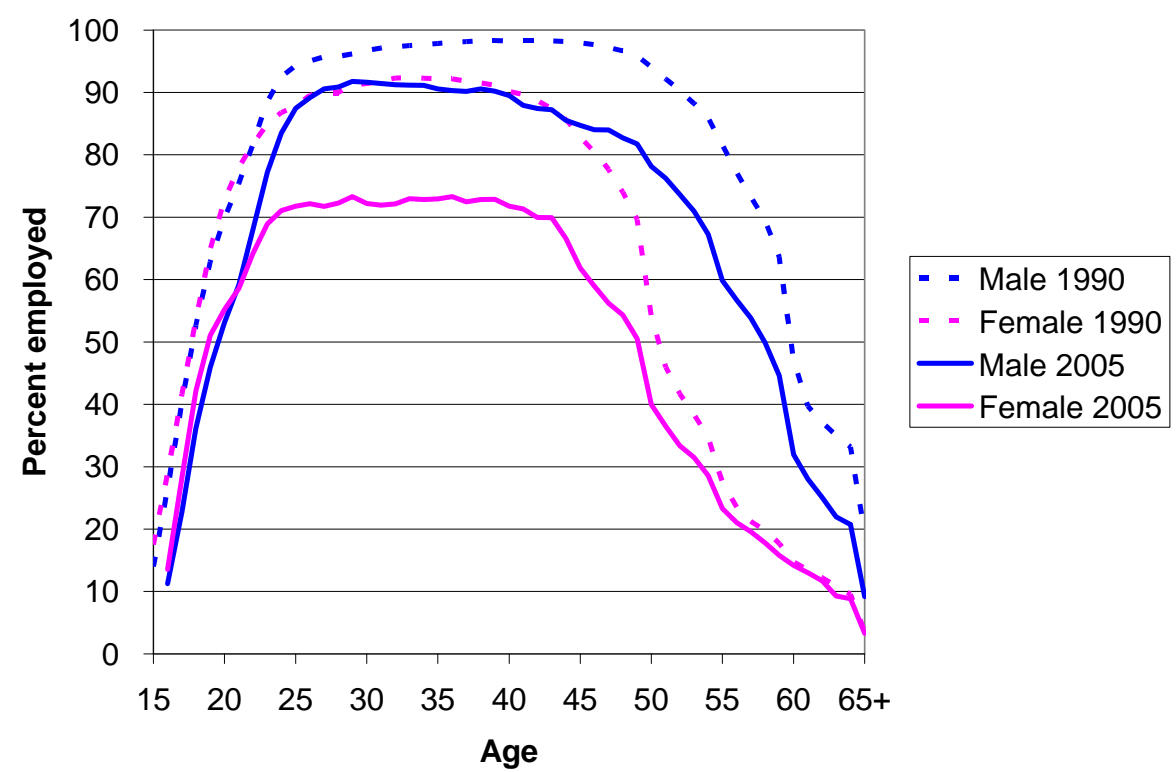

Sources: China State Council and China National Bureau of Statistics $(1993,2007)$

A fifth channel through which the observed changes in age structure will affect economic growth is human capital investment. With the declines in fertility rates observed over the last decades, school enrollment and educational attainment have improved across countries as parents opt to invest more in fewer, but more highly educated children. Lee and Mason (2010) summarize this point: "If small cohorts of workers have high levels of human capital because parents and/or taxpayers have invested more in each child, standards of living may rise despite the seemingly unfavorable age structure." Even more succinctly, they state: "The [effects] of population aging are reversed as large cohorts of less productive members are replaced with small cohorts of more productive members." Exhibit 18 summarizes the average human capital for the sample of 120 countries covered in Lutz, Goujon, K.C and Sanderson (Lutz, K.C., Goujon and Sanderson, 2007).

The average fertility rate declined from 4.82 to 2.65 between 1970 to 2000 , a period during which average years of schooling went up substantially. Among individuals aged 25-29, average years of schooling completed increased by 1.87 (males) and 2.58 years (females), respectively. The average number of schooling years for all individuals aged 25 and older went up from 4.03 in 1970 to 6.61 in 2000. The data displayed show a correlation of -0.85 between total years of schooling and contemporaneous fertility rates; on average, each unit drop in the total fertility rate is roughly associated with a 1.1-year increase in average years of schooling. Lee and Mason (Lee and Mason, 2010) argue that total human capital investment is in fact constant across the demographic transition, so that family size does not have a direct effect on the total human capital of a generation. This assertion implicitly assumes constant returns to scale to human capital investment, which appears slightly optimistic. 
Exhibit 18: Fertility and Human Capital 1970-2000.

\begin{tabular}{ccccc}
\hline \hline Year & Fertility & $\begin{array}{c}\text { Avg. years of schooling, } \\
\text { females, ages 25-29 }\end{array}$ & $\begin{array}{c}\text { Avg. years of schooling, } \\
\text { males, ages 25-29 }\end{array}$ & $\begin{array}{c}\text { Avg. years of schooling, } \\
\text { population 25+ }\end{array}$ \\
1970 & 4.82 & 5.03 & 6.66 & 4.03 \\
1980 & 3.66 & 5.99 & 7.48 & 4.92 \\
1990 & 3.11 & 6.79 & 7.91 & 5.82 \\
2000 & 2.65 & 7.61 & 8.53 & 6.61 \\
Absolute change 1970-2000 & -2.17 & 2.58 & 1.87 & 2.58 \\
Relative change 1970-2001 & $-45.02 \%$ & $51.29 \%$ & $28.08 \%$ & $64.02 \%$ \\
\hline \hline
\end{tabular}

While it is not clear to what degree more capital investment can compensate for smaller young cohorts, continued higher investment in schooling will undoubtedly increase the relative productivity of the smaller young cohorts. More productive young cohorts will not only directly contribute to economic growth, but also reduce the tax burden necessary to sustain growing older generations by increasing average income levels.

A sixth means by which society can adjust to population aging involves the participation of business. Because the elderly are healthier than in the past, they can work more productively for longer and place fewer demands on public resources. Businesses can play a role in encouraging older workers to continue working, and they can in turn benefit from such workers' experience and reliability. Allowing flexible schedules, offering ongoing training in new skills, providing wellness programs, and re-allocating physically demanding tasks to younger workers are measures that can help retain the older segment of the workforce. Moving from seniority-based pay to performance-based compensation will play a role in ensuring that businesses still find it worthwhile to keep older workers on the payroll.

So far, however, business has been slow to plan for population aging. Delay will not be an option for much longer as labor markets tighten, especially in Europe and Japan. Companies will soon have little choice but to be more welcoming of older employees. Indeed, prompt action to harness - and enhance - the contributions of older workers could become a key competitive advantage.

Businesses might benefit by changing some widespread practices and attitudes. Older workers are often seen as a burden, with younger candidates preferred in recruitment decisions. But in an economy where knowledge rules, the experience of older workers grows in value; older workers can contribute to the productivity of work teams by sharing their expertise. Older employees who wish to keep working may demand flexible roles and schedules. Allowing more part-time work and telecommuting would entice older workers to stay on, extending their careers by placing lighter burdens on their stamina. Likewise, allocating demanding physical tasks to younger employees would produce a similar benefit (and potentially reduce health care costs arising from workplace accidents). Ongoing training would help older workers master new skills as the economy changes. Moreover, employees' longer working lives give firms the benefit of greater productivity gains from their training investments. Investing in the health of all employees enhances productivity and avoids unnecessary costs as the workforce ages. Wellness programs produce healthier employees at all ages; on-site clinics save workers time and focus care on 
prevention and early disease detection, which also lowers costs. Finally, moving from pay systems that are seniority-based to ones that are performance-based would lead to a relaxation of corporate norms surrounding age at retirement.

In designing the organizations of the future, the private sector - with appropriate public-policy support - could choose to anticipate, rather than passively await, the trend toward longer lifespans and older employees. Although some adaptations lie on the more distant horizon, others could be undertaken right now, to the benefit of both younger and older employees - and of the firm itself. In June 2007 the German automaker BMW took stock of the age of its workforce and of the fact that it would have a much older profile ten years later - and decided to address the potentially decreasing productivity of assembly lines staffed by older workers. In an initiative that drew upon the cooperation of its factory's Workers Council and workers of all ages, it instituted a set of changes that raised productivity significantly. These changes included, for example, improving the ergonomics of machines and computer screens, making it easier for workers to rotate jobs, enhancing management of health care, and upgrading workers' skills (Loch et al 2010).

Finally, we note that economies respond to labor shortages by gradually increasing the capital-tolabor ratio. To the extent that population aging tends to reduce available labor, the natural response of firms, and of an economy as a whole, will be to invest in equipment that makes labor more productive.

\section{Summary and Discussion}

\section{Population pessimism redux}

For most of the $20^{\text {th }}$ century, the field of demography focused on the explosion in population numbers caused by lowered mortality rates and continuing high fertility rates. However, the predicted negative consequences of high population densities and population growth rates seem not to have been borne out, and many of these predictions seem in retrospect to have been unduly alarmist. For example, between 1960 and 1999, global population doubled, rising from 3 to 6 billion, but income per capita tripled, decisively refuting the predictions of population pessimists from Malthus to Ehrlich. ${ }^{13,14}$

Reflecting the growing influence of American economists, a 1986 National Academy of Sciences report on population growth established the non-alarmist position as the dominant viewpoint on population growth (Kelley, 2001). While rapid population growth certainly posed

\footnotetext{
${ }^{13}$ According to Malthus, who wrote around 1800, when world population first crossed the 1 billion mark, “...[population growth] appears ... to be decisive against the possible existence of a society, all the members of which should live in ease, happiness, and comparative leisure; and feel no anxiety about providing the means of subsistence for themselves and families." In a similar vein, Paul Ehrlich asserted in the late 1960s, that "The battle is over. In the 1970s hundreds of millions of people are going to starve to death." (Malthus, 1798; Ehrlich, 1968)

${ }^{14}$ According to the Penn World Tables (version 6.2), total global GDP per capita in 2000 was US\$7565 (at 2000 purchasing power parity). The same number in 1960 was US\$2495, which means that global GDP per capita has increased by $202 \%$ (or tripled) over the period $1960-2000$, at the same time as the total population doubled. In terms of growth rates, this corresponds to an average annual growth rate of $2.8 \%$.
} 
problems, the report argued that market mechanisms and non-market institutions were usually sufficiently flexible to overcome the related challenges. In particular, projections of the effects of population growth based on unchanged behavior elsewhere in the economy might give a very bleak picture, but in general would be very misleading. Changing incentives through price changes, and changing non-market institutional arrangements to promote new behaviors, could both have large effects and produce responses that would alleviate the problems associated with population growth.

The population debate focused on population numbers and largely neglected the issue of age structure changes. ${ }^{15}$ Population growth caused by rising fertility, and population growth caused by falling mortality, are likely to have quite different economic consequences because they have different age structure effects. We have examined some of these consequences above, but it is important to remember the lessons of the earlier debate. Analysis based on "accounting effects", in particular on the assumption that age-specific behavior remains unchanged as the age structure evolves, may be misleading. Caution is encouraged when this type of analysis predicts large reductions in welfare, as these are exactly the conditions that will produce incentives for behavioral change.

This reasoning also applies to an assessment of the economic growth implications of continued improvements in health and reductions in mortality into old age. How well countries address the challenge of population aging will largely depend on the flexibility of their respective markets and the appropriateness of their institutions and policies.

The preceding section explored the economic growth implications of population aging. The key premise is that labor supply, productivity, and savings vary over the life cycle. This implies that the age structure of a population may be consequential for its economic performance, as measured by income per capita. Large youth and elderly cohorts might slow the pace of economic growth, while large working-age cohorts might speed it. However, in addition to these "accounting" effects (assuming age-specific behavior remains unchanged we can simply calculate the consequences of age structure change mechanically) there are also behavioral effects. For example, increased longevity - a key driver of population aging - can change lifecycle behavior, leading to a longer working life, higher savings, and more investment in human capital.

One view is that population aging in the developed countries is likely to have a large effect, reducing income per capita primarily through the fall in labor supply per capita that will accompany the reduction in the share of working-age population. However, even if this occurs, it may not be as harmful as it at first appears for five reasons.

\footnotetext{
${ }^{15}$ An important exception to this disregard of age structure is World Bank (1994), which draws attention to rapid growth of the older segment of the population and to the weakening of traditional family support systems. The study calls for the development of both public and private "pillars" of an economic security system for the elderly, to supplement individual voluntary measures. Above all, it called for countries to give immediate attention to the issues brought about by population aging.
} 
First, as seen in the previous section, rough estimates of the magnitude of the effect of population aging on the rate of labor force participation and the concomitant effect of changes in labor force participation on economic growth are of modest size for most countries.

Second, income per capita, in itself, is not a welfare measure. Nordhaus (Nordhaus, 2003) estimates that improvements in longevity over the $20^{\text {th }}$ century made a contribution to increasing welfare in the United States of roughly the same magnitude as the rise in consumption levels. The longer life expectancies that lead to aging can be thought of as improving welfare directly by expanding the population's lifetime budget set. Even if rising life expectancy were to lead to reduced consumption levels per period, it is difficult to argue that the net effect of increased longevity on welfare will be negative.

Third, welfare depends on consumption, not income. Typically household income falls at retirement, while consumption may remain relatively high. It is feasible that one could observe two populations, each enjoying the same consumption stream over the same lifespan, but the population with a larger elderly age cohort will have lower per capita income. For these populations, income per capita would vary with the age structure, but lifetime welfare would be equal. Thus, aging-induced declines in income per capita are not necessarily indicative of corresponding declines in welfare. ${ }^{16}$

Fourth, the consequences of a slowing in per capita income growth may not be disastrous for welfare, and it is not clear that population aging will reduce the growth rate of income per capita at all. Increases in life expectancy in the United States over the last two centuries have been associated with reductions in the age-specific incidence of disease, disability, and morbidity (Fogel, 1994; Fogel, 1997; Costa, 1998). Mathers and others (2001) show that health-adjusted life expectancy (each life year weighted by a measure of health status) rises approximately one for one with life expectancy across countries. Other studies, mostly conducted in the US and other wealthy industrial countries, imply a compression of the morbid years - both relatively and absolutely - as life expectancy rises. Individuals can respond to an expectation of longer healthy lifespans by working longer or saving more (i.e., consuming less). A longer working period allows for a sustained high consumption level during old age, with a similar savings rate as before the increase in life expectancy. If individuals decide to take extra leisure and retire at the same age as before, they will have lower consumption levels throughout their life and will need higher savings rates while working. Bloom, Canning, and Graham (2003) examine this issue theoretically and argue that when health improves and longevity rises the optimal response is likely to be a longer working life, without the need for higher savings. ${ }^{17}$ To the extent that working lives lengthen in response to longer lifespans, there is no reduction in income levels; average income and consumption per capita can indeed remain high. The assumption of fixed, age-specific rates of labor force participation assumes no behavioral change when in fact such changes may occur.

\footnotetext{
${ }^{16}$ A related point: When people retire, they often begin to work as volunteers, or they do more to help with family tasks - activities that are not counted in a country's output. If they work longer, some of those tasks would have to be carried out by paid labor or would not be carried out at all.

${ }^{17}$ The tendency towards early retirement is explained by an income effect with people wanting more leisure time as incomes rise.
} 
Fifth, old age "dependency" is something of a misnomer. Lee (2000) shows that, in all preindustrial societies for which he was able to assemble evidence, the flow of transfers is from the middle aged and old to the young. In developed countries, on the other hand, both the young and the old benefit from government transfers, and the net pattern of transfers is towards the elderly. However, at the household level in the United States, elderly households make significant transfers to middle aged households, undoing to some extent the effects of government policy. The dependency burden of the elderly is thus a function of the institutional welfare systems that are in place rather than an immutable state of affairs. ${ }^{18}$

Analysis of the effects of the expected population aging on economic growth represents virgin territory, due to the unprecedented size and nature of the current demographic shift. Past experience cannot provide a guide, and demographers and economists therefore need to rely on models.

Insofar as population aging leads to labor supply reductions that cause wages to rise, and given that different countries are in different phases of the demographic cycle, international migration flows are likely to be stimulated. Such flows would smooth the age distribution since workingage individuals account for a large proportion of international migrants. However, judging by historical experience, and in a context of widespread institutional and social constraints on immigration, the magnitude of the increases needed to smooth the age distributions is inordinately large and not, as a practical matter, likely to be a decisive response to population aging. Although migrants themselves benefit greatly, moreover, it is not yet well established whether immigration results in net economic benefits or losses to receiving countries.

\section{The importance of policy}

The policy environment plays a crucial role in determining the effect of aging on economic growth. The problem of population aging is more a function of rigid and outmoded policies and institutions than a problem of demographic change per se. New policies will be needed if countries are to take account of the natural incentives individuals face to adjust their behavior in the wake of population aging.

Among the most commonly mooted policy changes is to alter retirement incentives so that people can fulfill their expressed desires to work longer in response to expectations of greater longevity. More flexible old-age pension arrangements combined with increases in the official retirement age would encourage prolonged workforce participation. Legal and cultural efforts to discourage age discrimination by employers may also be required. Lifelong education programs could assist in these efforts, by helping people adapt their skills and knowledge to the demands of a changing economy.

Investment in improving the health of those aged 60 or over is a further policy option. This approach reduces the burden on health care and social security systems and enables people to work for longer by compressing morbidity into fewer years late in life. As Zweifel, Felder, and

\footnotetext{
${ }^{18}$ Mason et al. (Mason, Lee, Tung, Lai and Miller, 2006) propose and investigate a National Transfer Accounts methodology to aid in understanding the extent and effect of intergenerational transfers.
} 
Meiers (1999) have shown, health care costs appear to be concentrated in the last few years of life regardless of age, so population aging defers rather than increases costs per person. In addition to easing strains on state finances, the compression of morbidity will enable older people to continue to contribute their expertise and knowledge to economies.

Policies can also encourage increased labor force participation more generally. Laws against sex discrimination and increased support for child care have helped open up the workplace to women in many wealthy countries, and middle- and low-income countries with aging populations would likely benefit from similar measures. Upward pressure on wages is likely to increase women's participation in the workforce, and this can be complemented by policies that facilitate mothers combining work and family, such as state-funded childcare and more flexible working hours. The latter, of course, also incentivizes childrearing, with long-term impacts on the age structure.

Immigration can also make a big difference; policymakers in aging developed countries have not yet successfully made the case for increased immigration from the developing world, but demographic imbalances mean demand by employers is likely to intensify in the coming decades. Compensating those who lose out from the process (such as low-skilled receivingcountry workers) might render opening up to migration more politically feasible.

A further important policy consideration is addressing the funding gap caused by the intergenerational transfers implicit in pay-as-you-go health and pension systems. ${ }^{19}$ In an aging society, pay-as-you-go systems mean that increasingly small cohorts of working-age people will make transfers to increasingly large cohorts of elderly. Policies that can help reduce old age "dependency" include adjusting premiums and benefits or making a transition to full funding or a system of private accounts, whereby individuals effectively draw at least part of their pensions from investments made during their time in work. Fully funded systems mean that older workers who continue working benefit by having a larger sum to draw on when they eventually retire. Moving toward such a system would require robust institutions that can both attract sufficient savings and invest them productively and safely, as well as financial reserves to pay the transition for the older generation with insufficient private savings. There are some concerns that the increases in savings required in moving away from a pay-as-you-go system will result in scarcer investment opportunities and diminished returns. Although Poterba (2004) finds that the historic effect of demography on real rates of return has been small, Turner (2006) injects some major caveats into this discussion: (a) higher savings rates will tend to lower returns on investments; (b) when new generations are smaller, both pay-as-you-go and fully-funded pension systems will face falling asset prices, so the latter are not a cure-all for troubled pension systems; and (c) the performance of funded systems depends on global capital markets, not just those of any particular country. Turner concludes that fully funded systems will not necessarily provide a complete answer to demographic change and that pay-as-you-go systems can be adjusted to achieve "many of the supposed advantages of funded systems". Heller (2003) emphasizes the fact that the historically unprecedented commitments governments have already made to financial support of the elderly will play a major constraining role in future policymaking in this

\footnotetext{
${ }^{19}$ Weil (Weil, 2008) highlights the importance of this issue in saying, "The most important means by which ageing will affect aggregate output is the distortion from taxes to fund public pensions."
} 
area. ${ }^{20,21}$ Countries that have not yet made such commitments have more flexibility in pension system design.

Crafting effective policies regarding aging that both serve the needs of the elderly and are consistent with the financial resources that countries can bring to bear is a difficult task, but efforts are underway to tackle it. An international group drawing on members of the national science academies of China, India, Indonesia, Japan, and the United States has focused on the importance of using science to inform policy. On a parallel track, detailed by J. Lee (2010), researchers in China, Europe, Korea, Mexico, India, Indonesia, Japan, Thailand, the United Kingdom, and the United States have been striving to carry out harmonized surveys aimed at understanding the financial, social, and health status of the elderly, with the aim of aiding policy formation and providing inputs for cross-national research.

\section{An uncertain future}

Of course, humility is required when making recommendations and, even more so, decisions based on future demographic projections. The sources of uncertainty remain considerable, and projections of population size and structure can change quite significantly even over short periods. The possibility of significant changes in fertility behavior or new health shocks could tilt the balance between young and old in unforeseen ways. Longevity projections are also precarious and hotly debated. Trends in diet and lifestyle as well as medical and public health advances could combine to raise or lower life expectancy in the future, and technology has a crucial role to play. The compression of morbidity occurring today is partly driven by new health technology, but it is uncertain whether technological advance will continue, diminish, or accelerate in future, and what cost implications it will have. Trends such as the so-called obesity epidemic could dampen the positive effects of technology. WHO projects that by 2015,700 million people will be obese (WHO, 2006); WHO also notes that the health impacts of rising obesity prevalence could reverse life expectancy gains in some countries (Visscher and Seidell, 2001). Non-health-related events such as climate change or war could also have an unpredictable effect on longevity.

The economic impacts of aging are unlikely to be uniform across societies. In the developed world, longer lifespans have been accompanied by a shift in support for older generations from families to the state. In many developing countries, families remain pivotal to elder care and as lifespans becomes longer there may be disruption to family structures, leading to a move towards public transfer systems and savings similar to that experienced in wealthier parts of the world.

More broadly, one cross-cutting observation is clear: Developed and developing countries differ from each other greatly in the pace and extent of their progress through the demographic transition and in the financial and institutional resources they have available in responding to population aging. Although aging will be rapid in many developing countries, the countries that

\footnotetext{
${ }^{20}$ Auerbach, Kotlikoff, and Leibfritz (Auerbach, Laurence J. Kotlikoff and Leibfritz, 1999) review the use of generational accounting as a means of studying these and broader questions about intergenerational transfers.

${ }^{21}$ Barr and Diamond (Barr and Diamond, 2006) systematically address many of the issues and controversies in the arena of pensions and their distributional effects, savings, and economic growth.
} 
are immediately faced with the issue of population aging are mainly in the developed world, where pension systems and health care systems are facing unprecedented challenges. But developed countries are also more financially capable of responding to the challenges posed by population aging, because they became "rich" before they became - or will become - "old".

The rapid aging of the population in developing countries means that those countries will, to at least some extent, become "old" before they become "rich" - a situation that will be much more challenging than what the developed world has faced. To cite just one example, establishing financially viable pension systems will be much more difficult for developing countries that are experiencing population aging than it has been for developed countries. Beyond basic resource constraints, the predominance of informal sector labor in developing countries makes the design and implementation of such systems all the more difficult. ${ }^{22}$

Although drawing lessons from the past may not be possible for an aging future, we can take comfort in the fact that some societies have coped well with large-scale population growth in the past century. The world economy has had the flexibility to absorb and in general benefit from dramatic increases in population numbers. If today's policymakers take prompt action to prepare for the effects of aging, the next major shift is likely to cause much less hardship than many anticipate.

22 Bloom, Mahal, Rosenberg, and Sevilla (2010a) discuss India's efforts to provide social security to its population, a major challenge due to rapid population aging, substantial rural-to-urban migration, the weakening of family support systems, and the continued predominance of informal sector labor. The central government and the states of India have responded with an array of programs to support the elderly and other groups, such as women, who are particularly vulnerable to economic insecurity. Nevertheless, economic insecurity for most Indians remains high. 


\section{References}

Auerbach, A. J., Laurence J. Kotlikoff and W. Leibfritz (1999). Generational Accounting around the World. National Bureau of Economic Research Project Report. Chicago, University Of Chicago Press.

Banister, J., D.E. Bloom, and L. Rosenberg, "Population Aging and Economic Growth in China”, PGDA Working Paper \#53.2010, http://www.hsph.harvard.edu/pgda/WorkingPapers/2010/PGDA_WP_53.pdf

Barr, N. and P. A. Diamond (2006). "The Economics of Pensions." Oxford Review of Economic Policy 22(1): 15-39.

Bloom, D.E. and D. Canning, "Global Demographic Change: Dimensions and Economic Significance", Population and Development Review vol. 33(supplement), Population Council, New York, 2008, 17-51.

Bloom, D. E., D. Canning, G. Fink and J. E. Finlay (2007). "Demographic Change, Institutional Settings, and Labor Supply." mimeo.

Bloom, D. E., D. Canning, G. Fink and J. E. Finlay (2009). "Fertility, Female Labor Force Participation, and the Demographic Dividend." Journal of Economic Growth 14(2): 79101.

Bloom, D. E., D. Canning, G. Fink, and J. E. Finlay (2010). "The Cost of Low Fertility in Europe", European Journal of Population; 26:141-158.

Bloom, D. E., D. Canning and B. Graham (2003). "Longevity and Life-Cycle Savings." Scandinavian Journal of Economics 105(3): 319-38.

Bloom, D.E., D. Canning, and P. Malaney (2000). "Demographic Change and Economic Growth in Asia", Population and Development Review 26: 257-290.

Bloom, D. E., D. Canning, R. K. Mansfield and M. Moore (2007). "Demographic Change, Social Security Systems and Savings." Journal of Monetary Economics 54: 92-114.

Bloom, D. E., D. Canning and J. Sevilla (2003). "The Demographic Dividend: A New Perspective on the Economic Consequences of Population Change." Population Matters Monograph MR-1274, RAND, Santa Monica.

Bloom, D. E., A. Mahal, L. Rosenberg, and J. Sevilla, (2010a). "Economic security arrangements in the context of population ageing in India". International Social Security Review. Special issue on "Social security and the challenge of demographic change".

Bloom, D. E., A. Mahal, L. Rosenberg, and J. Sevilla, (2010b). "Enhancing Social Protection Initiatives in the Developing Member Countries". Report prepared for the Asian Development Bank.

Bloom, D. E. and J. G. Williamson (1998). "Demographic transitions and economic miracles in emerging Asia." World Bank Economic Review 12(3): 419-455.

Burtless, G. and R. A. Moffitt (1985). "The Joint Choice of Retirement Age and Postretirement Hours of Work " Journal of Labor Economics 3(2): 209-236.

China State Council, Office of the National 1\% Population Sample Survey Leading Group, and China National Bureau of Statistics, Department of Population and Employment Statistics, (2007). 2005 National 1\% Population Sample Survey Data. [In Chinese] Beijing: China Statistics Press. Table 3-1a, pp. 150-152; Table 5-2a, pp. 228-237.

China State Council, Population Census Office, and China National Bureau of Statistics, Department of Population Statistics, (1993). Tabulation on the 1990 Population Census 
of the People's Republic of China, 4 volumes. [In Chinese] Beijing: China Statistics Press. Table 6-10, Vol. 2, pp. 490-503.

Costa, D. (1998). The Evolution of Retirement: An American Economic History 1880-1990. Chicago, University of Chicago Press.

Dor, A., C. Ferguson, C. Langwith, and E. Tan (2010). A Heavy Burden: The Individual Costs of Being Overweight and Obese in the United States". Research Report. George Washington University. http://www.gwumc.edu/sphhs/departments/healthpolicy/pdf/HeavyBurdenReport.pdf

Dychtwald, K. (1999). Ken Dychtwald on the Future. San Francisco Chronicle. San Francisco. November 15.

Ehrlich, P. (1968). The Population Bomb. New York, Ballantine Books.

European Commission (2010). "Green paper: Towards adequate, sustainable and safe European pension systems." http://ec.europa.eu/social/BlobServlet?docId=5551\&langId=en

euobserver.com (2010). "Brussels suggests raising retirement age for EU citizens" http://euobserver.com/9/30160

European Union, Economic Policy Committee, Working Group on Ageing Populations and Sustainability. http://europa.eu/epc/working_groups/ageing_en.htm Accessed August $25,2010$.

Fogel, R. W. (1994). "Economic Growth, Population Theory, and Physiology: The Bearing of Long-Term Processes on the Making of Economic Policy." American Economic Review 84: 369-95.

Fogel, R. W. (1997). New Findings on Secular Trends in Nutrition and Mortality: So Implications for Population Theory. Handbook of Population and Family Economics. M. Rosenzweig and O. Stark, eds. Amsterdam, Elsevier. 1A.

Fries, J. (1980). "Aging, Natural Death and the Compression of Morbidity." New England Journal of Medicine 303: 130-35.

Greenspan, A. (2003). Aging Global Population. Testimony before the Special Committee on Aging, U.S. Senate.

Gruber, J. and D. Wise (1998). "Social Security and Retirement: An International Comparison." The American Economic Review 88(2): 158-163.

Heller, P. S. (2003). Who Will Pay: Coping with Aging Societies, Climate Change, and Other Long-Term Fiscal Challenges. Washington, D.C., International Monetary Fund.

ILO Bureau of Statistics (2009). ILO Database on Labour Statistics, International Labour Organization.

International Labor Organization (2008). "Can low-income countries afford basic social security?" Paper 3, Social Security Policy Briefings. Geneva: International Labor Organization.

Kelley, A.C. (2001). "The Population Debate in Historical Perspective: Revisionism Revised", in Birdsall, N., A.C. Kelley, and S.W. Sinding, eds., Population Matters: Demographic Change, Economic Growth, and Poverty in the Developing World. Oxford: Oxford University Press. Pp. 24-54.

Krugman, P. (2010). "Attacking Social Security". The New York Times. August 15. Kulish, M., K. Smith and C. Kent (2006). "Ageing, Retirement and Savings: A General Equilibrium Analysis." Reserve Bank of Australia Research Discussion Paper (2006-06). 
Lee, J. (2010). "Data sets on pensions and health: Data collection and sharing for policy design". International Social Security Review. Special issue on "Social security and the challenge of demographic change".

Lee, R. (2000). A Cross-Cultural Perspective on Intergenerational Transfers and the Economic Life Cycle. Sharing the Wealth: Demographic Change and Economic Transfers between Generations. A. Mason and G. Tapinos. Oxford University Press: 17-56.

Lee, R. and A. Mason (2010). "Fertility, Human Capital, and Economic Growth over the Demographic Transition.". European Journal of Population 26: 159-182.

Loch, C.H., F.J. Sting, N. Bauer, and H. Mauermann (2010). "How BMW Is Defusing the Demographic Time Bomb.” Harvard Business Review. March. 99-102.

Lutz, W., A. Goujon, S. K.C., and W. Sanderson (2007). "Reconstruction of population by age, sex and level of educational attainment of 120 countries for 1970-2000". Vienna Yearbook of Population Research, vol. 2007, pp 193-235.

Lutz, W., W. Sanderson and S. Scherbov (2008). "The Coming Acceleration of Global Population Ageing." Nature 451: 716-19.

Malthus, T. R. (1798). An Essay on the Principle of Population as It Affects the Future Improvement of Society, with Remarks on the Speculations of Mr. Godwin, M. Condorcet, and Other Writers. London, J. Johnson.

Mason, A., R. Lee, A.-C. Tung, M.-S. Lai and T. Miller (2006). "Population Aging and Intergenerational Transfers: Introducing Age into National Accounts." NBER Working Paper 12770.

Mathers, C. D., R. Sadana, J. A. Salomon, C. J. Murray and A. D. Lopez (2001). "Healthy life expectancy in 191 countries, 1999." Lancet 357(9269): 1685-91.

McKibbin, W. J. (2006). "The Global Macroeconomic Consequences of a Demographic Transition." The Australian National University Centre for Applied Macroeconomic Analysis Working Paper 6/2006.

Nordhaus, W. (2003). The Health of Nations: The Contribution of Improved Health to Living Standards. Measuring the Gains from Medical Research: An Economic Approach. K. H. Murphy and R. H. Topel. Chicago, University of Chicago Press.

Peterson, P. G. (1999). "Gray Dawn: The Global Aging Crisis." Foreign Affairs (January/February).

Poterba, J.M. (2004). "Impact Of Population Aging on Financial Markets in Developed Countries," Federal Reserve Board of Kansas City. Economic Review 89(4), 43-53.

Preston, S. H. (1975). "The Changing Relation between Mortality and Level of Economic Development." Population Studies 29(2): 231-48.

Sanderson, W.C., and S. Scherbov (2010). "Remeasuring Aging." Science 239: 1287-1288.

Sanderson, W., and S Scherbov (2008). "Rethinking Age and Aging," Population Bulletin 63 (4). www.prb.org/pdf08/63.4aging.pdf

Social Security Administration, United States (2010). Social Security Programs Throughout the World: The Americas, 2009. http://www.ssa.gov/policy/docs/progdesc/ssptw/20082009/americas/index.html

Turner, A. (2006). "Pension Challenges in an Aging World." Finance \& Development 43(3): 3639.

Tyers, R. and Q. Shi (2007). "Global Demographic Change, Policy Responses and Their Economic Implications." The World Economy 30(4): 537-66. 
United Nations (2009). World Population Prospects: The 2008 Revision. CD-ROM Edition Extended Dataset United Nations.

Visscher, T. L. and J. C. Seidell (2001). "The Public Health Impact of Obesity." Annual Revue of Public Health 22: 355-75.

Weil, D. N. (2008). "Population Ageing." The New Palgrave Dictionary of Economics. Volume 6, second edition: 499-503.

World Bank (2007). World Development Indicators 2007. Washington: The World Bank.

World Bank (1994). Averting the Old Age Crisis: Policies to Protect the Old and Promote Growth. New York: Oxford University Press.

World Economic Forum (2004). "Living Happily Ever After: The Economic Implications of Aging Societies". Executive Summary of a Report to the World Economic Forum Pension Readiness Initiative. Geneva: World Economic Forum.

World Health Organization (2006). "Obesity and overweight". http://www.who.int/mediacentre/factsheets/fs311/en/index.html

Zweifel, P., S. Felder and M. Meiers (1999). "Ageing of Population and Health Care Expenditure: A Red Herring?" Health Economics 8(6): 485-496. 